\title{
The Development of Disease-Modifying Therapies for Osteoarthritis (DMOADs): The Evidence to
} Date

\author{
Win Min Oo $\mathbb{D}^{1,2}$ \\ Christopher Little $\mathbb{D}^{3}$ \\ Vicky Duong' \\ David J Hunter (1)
}

\begin{abstract}
'Rheumatology Department, Royal North Shore Hospital, and Institute of Bone and Joint Research, Kolling Institute, Faculty of Medicine and Health, The University of Sydney, Sydney, Australia; ${ }^{2}$ Department of Physical Medicine and Rehabilitation, Mandalay General Hospital, University of Medicine, Mandalay, Mandalay, Myanmar; ${ }^{3}$ Raymond Purves Bone and Joint Research Laboratories, Institute of Bone and Joint Research, Kolling Institute, Faculty of Medicine and Health, The University of Sydney, Sydney, Australia
\end{abstract}

\begin{abstract}
Osteoarthritis (OA) is a complex heterogeneous articular disease with multiple joint tissue involvement of varying severity and no regulatory-agency-approved diseasemodifying drugs (DMOADs). In this review, we discuss the reasons necessitating the development of DMOADs for OA management, the classifications of clinical phenotypes or molecular/mechanistic endotypes from the viewpoint of targeted drug discovery, and then summarize the efficacy and safety profile of a range of targeted drugs in Phase 2 and 3 clinical trials directed to cartilage-driven, bone-driven, and inflammation-driven endotypes. Finally, we briefly put forward the reasons for failures in OA clinical trials and possible steps to overcome these barriers.
\end{abstract}

Keywords: osteoarthritis, DMOADs, disease-modifying drugs, intra-articular therapy, phenotype, endotype

\section{Why is the Development of Disease-Modifying Osteoarthritis Drugs (DMOADs) Required? Disease Burden}

Osteoarthritis (OA) is the most prevalent arthritis globally and represents a major challenge for twenty-first century health care systems. ${ }^{1,2}$ The Global Burden of Disease 2020 report showed an increase of $9.3 \%$ and $8.2 \%$ in the age-standardized OA point prevalence and annual incidence rate from 1990 to $2017 .^{3}$ The prevalence rises with increasing age; in the USA (United States of America), OA was found in $13.9 \%$ of adults aged $\geq 25$ years and $33.6 \%$ for those aged $\geq 65$ years respectively in $2005 .{ }^{4}$ The lifetime risk of having symptomatic knee OA is about $40 \%$ in men and $47 \%$ in women, and the risk increases to $60.5 \%$ among obese persons. ${ }^{5}$ By the year 2040 , an estimated $25.9 \%$ of the total adult population will have doctor-diagnosed arthritis in the USA. ${ }^{6}$

Globally, $80 \%$ of patients with OA suffer from limitations in movement, and $25 \%$ from difficulty in performing their major daily activities of life; representing a significant impact of $\mathrm{OA}$ on functional impairment and disability. ${ }^{7}$ In terms of economic burden, mean per-person earnings losses caused by OA were, on average, 7548 US\$ per year from 2008 to $2011 .^{8}$ The mean all-cause health care utilization of working-age patients with OA is $\$ 14,521$ US\$ per year. ${ }^{9}$ The socio-economic costs of OA were reported to range between $0.25 \%$ and $0.50 \%$ of a country's GDP. ${ }^{10}$ In an individual patient data meta-analysis, the pooled estimate for
Correspondence: David J Hunter Rheumatology Department, Royal North Shore Hospital, and Institute of Bone and Joint Research, Kolling Institute, Faculty of Medicine and Health, The University of Sydney, Sydney, Australia

Email david.hunter@sydney.edu.au 
premature mortality revealed a $23 \%$ increased risk $(95 \%$ CI $1.07,1.42)$ in patients with knee OA and a $20 \%$ increased risk (95\% CI 1.04, 1.37) in hip OA. ${ }^{11}$

\section{Unmet Needs for Disease-Modifying Drugs}

Current OA treatment options are focused on symptomatic improvement in pain and joint function and include paracetamol, nonsteroidal anti-inflammatory drugs (NSAIDs), opioid analgesics, and intra-articular medications such as steroids and hyaluronic acids. ${ }^{14}$ Surgical treatments are typically indicated only for patients with end-stage OA, as a last resort. Recently, paracetamol and opioids are only conditionally or not recommended by several scientific organisations, ${ }^{12,13}$ highlighting the importance of finding new effective treatments for OA. In addition, outcomes for patients with $\mathrm{OA}$ are usually suboptimal and patients remain vulnerable to the clinical consequences of the disease on pain and physical function. ${ }^{14}$

OA was previously regarded as a degenerative disorder resulting from cartilage damage, ${ }^{15}$ however, the development and utilization of modern imaging methods revealed that it results from the failure of the joint organ with a heterogeneous involvement of the whole joint structures, including cartilage damage, subchondral bone remodeling, synovial inflammation and osteophyte development. ${ }^{16}$ Therefore, OA can be defined as a complex heterogeneous syndrome with multiple joint tissue involvement of varying severity. In part as a consequence, it is a huge challenge to develop a single 'one size fits all' therapy that may be suitable and effective for all patients with OA. ${ }^{17}$

\section{Disease-Modifying Osteoarthritis Drugs (DMOADs)}

The central hallmark in the pathologic process of OA disease is the progressive deterioration in the biological, structural and mechanical properties and function of the joint tissues, and an effective medical treatment should possess the ability to delay these processes or ideally even halt them completely. Such pharmaceutical agents that will alter the natural history of disease progression by arresting joint structural change and ameliorating symptoms, either by reducing pain or improving physical function are termed as "DMOADs". ${ }^{18}$

Currently, regulatory bodies such as US Food and Drug Administration (FDA) ${ }^{19}$ and the European Medicines Agency $(\text { EMA })^{20}$ have not approved any drug as an effective DMOAD, as the approval guide requires a potential DMOAD to demonstrate a slowing in the loss of knee or hip joint space width (JSW) on x-ray with associated symptomatic improvement. ${ }^{17}$ Therefore, current OA trials for DMOAD development pipeline need to meet both clinically meaningful symptom improvement with concomitant structural benefits according to US FDA's published draft industry guidance on structural endpoints for OA published in 2018. ${ }^{18}$

\section{OA Subtypes: Phenotypes and Endotypes}

Because OA is characterised by its extraordinary interpatient variability in clinical and structural manifestations, identification of patient/disease subtypes appropriate for targeted therapy is probably one of the promising ways forward in drug development research. ${ }^{21,22}$ In addition, structural changes in $\mathrm{OA}$ result from complex interactions among different pathobiological pathways, which implicate a variety of catabolic factors and cytokines in the different joint tissues (molecular cross-talk). ${ }^{23}$ Therefore, a new model of classifying OA based on pathophysiological disease subtypes is needed.

These subtypes can be clinical phenotypes or molecular/ mechanistic endotypes. ${ }^{24} \mathrm{~A}$ clinical phenotype can be defined as a group of observable traits (ie aetiologic factors, risk factors) that can identify and characterize a subtype in a defined population. ${ }^{25,26}$ In other words, these subgroups of patients have similar clinically observable characteristics for better identifying individuals who are at higher risk of progression (prognostic) or who are more likely to respond to a specific intervention (prescriptive). ${ }^{27,28}$

An endotype is a disease subtype defined by distinct pathophysiologic mechanisms, including cellular, molecular and biomechanical signalling pathways. ${ }^{29}$ Therefore, the endotype is distinct from a phenotype, and indicates the presence of a well-defined molecular mechanism. A given clinical phenotype of OA may comprise overlapping molecular endotypes (ie, different mechanisms giving rise to the same manifestation at varying degrees during different phases of the disease). ${ }^{24}$

From the point of view of targeted drug discovery, where identifying and directing the right pathobiological mechanism and structural manifestations of disease is key for success, drug development in OA should be based on the endotypes as the basis of the main drivers of OA disease. $^{30}$ In this review, we will, therefore, focus on currently ongoing phase 2 and 3 clinical trials of active drug development (Figure 1) related to three main 


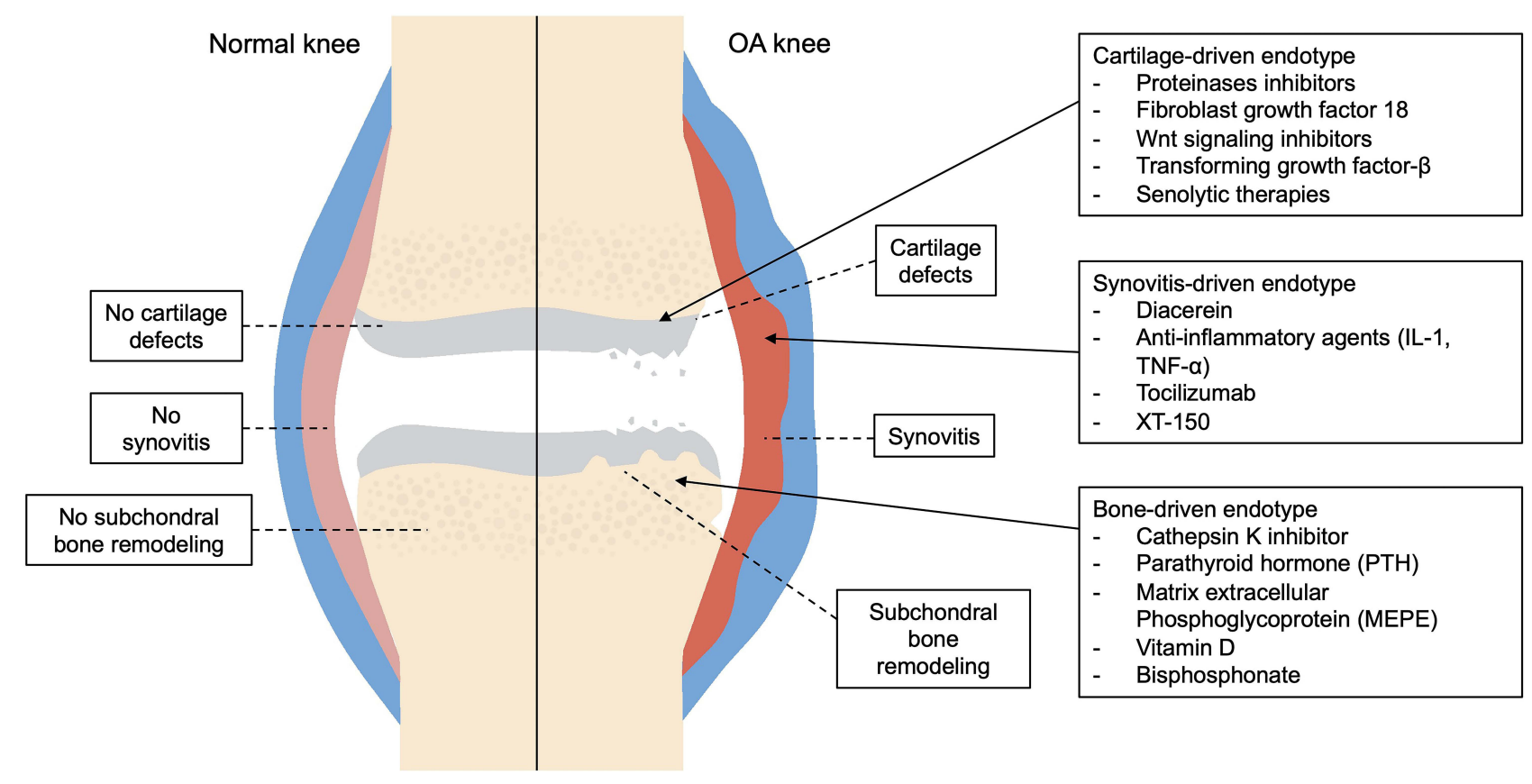

Figure I Active drugs related to the three main molecular or mechanistic OA endotypes (phase 2 and 3).

molecular/mechanistic endotypes: 1) Cartilage-driven endotype, 2) Bone-driven endotype, 3) Inflammationdriven endotype. While each drug has been assigned to and is discussed under one endotype based on its predominant activity, a particular therapeutic may have broader endotype-effects and where present, these are duly noted.

One author (WMO) conducted electronic and manual searches on the https://clinicaltrials.gov/ for identifying ongoing phase $2 / 3$ clinical trials in active drug development pipelines, as well as electronic database searches in the PubMed and Embase via Ovid for published reports of phase-2/3 clinical trials results from the inception of these databases to 31st March 2021 using the following MESH or keywords: osteoarthritis OR osteoarthrosis AND DMOAD/ OR structure modification OR diseasemodifying osteoarthritis drugs/.

\section{What Developments Have There Been in Clinical OA Trials Currently in Active Phase 2 and 3 Trials? Cartilage-Driven Endotype}

Cartilage damage is considered as a central part of OA disease process, which involves a variety of catabolic and reparative mechanisms at the molecular level. The pharmaceutical drugs in phase 2 and 3 stages of development for cartilage-driven endotype are summarized in Table 1.

\section{Proteinases Inhibitors (PI)}

Matrix-degrading enzymes in the joint such as collagenases and aggrecanases are responsible for proteolysis of extracellular matrix components such as type II collagen and aggrecan, which is the most abundant proteoglycan in cartilage. $^{31}$ Proteinases such as matrix metalloproteinase 13 (MMP13) and ADAMTS5 (a Disintegrin And Metalloproteinase with ThromboSpondin-motif-5) are involved in cartilage destruction and progression of cartilage damage in OA pre-clinical models. ${ }^{32,33}$ The potential benefits of MMP inhibitors in preserving the OA joint have been investigated. However, in patients with knee OA, broad-spectrum MMP inhibitors such as PG-116800 showed reversible musculoskeletal toxicities in a dosedependent manner without clinical benefits, leading to the termination of further development of this drug. ${ }^{34}$

S201086/GLPG1972 is a potent and highly selective active site inhibitor of ADAMTS5. It possesses an excellent selectivity profile in animal models and high stability in dog and human liver microsomes and hepatocytes. ${ }^{35}$ Phase-1 clinical studies revealed favorable pharmacokinetics as well as a strong and consistent target engagement in both healthy subjects and OA patients $(n=171) .^{36}$ In a phase-2 study (Roccella study) which investigated the efficacy and safety profile of three different once-daily oral doses of GLPG1972/S201086 $(n=932)$, the change in 


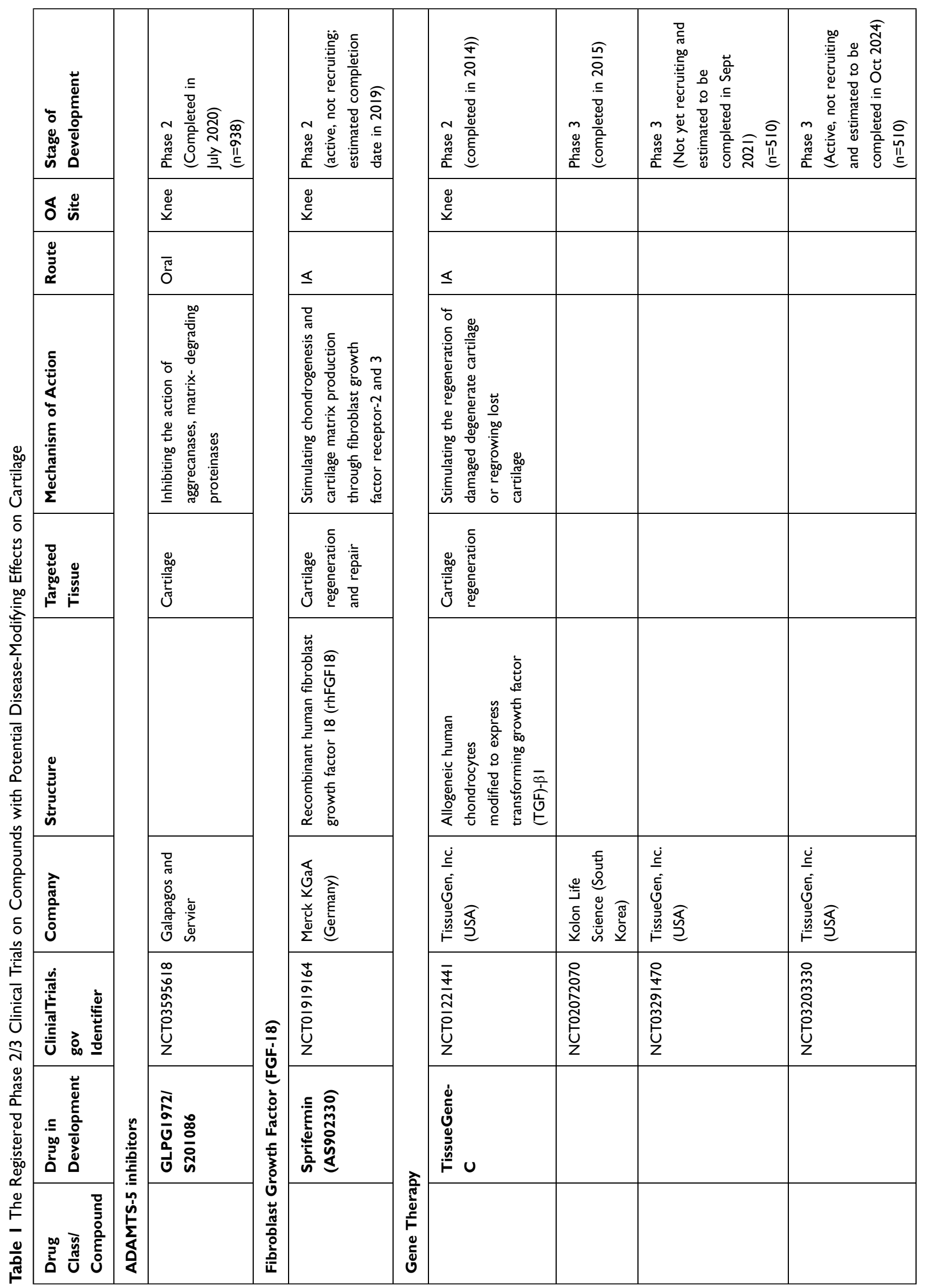




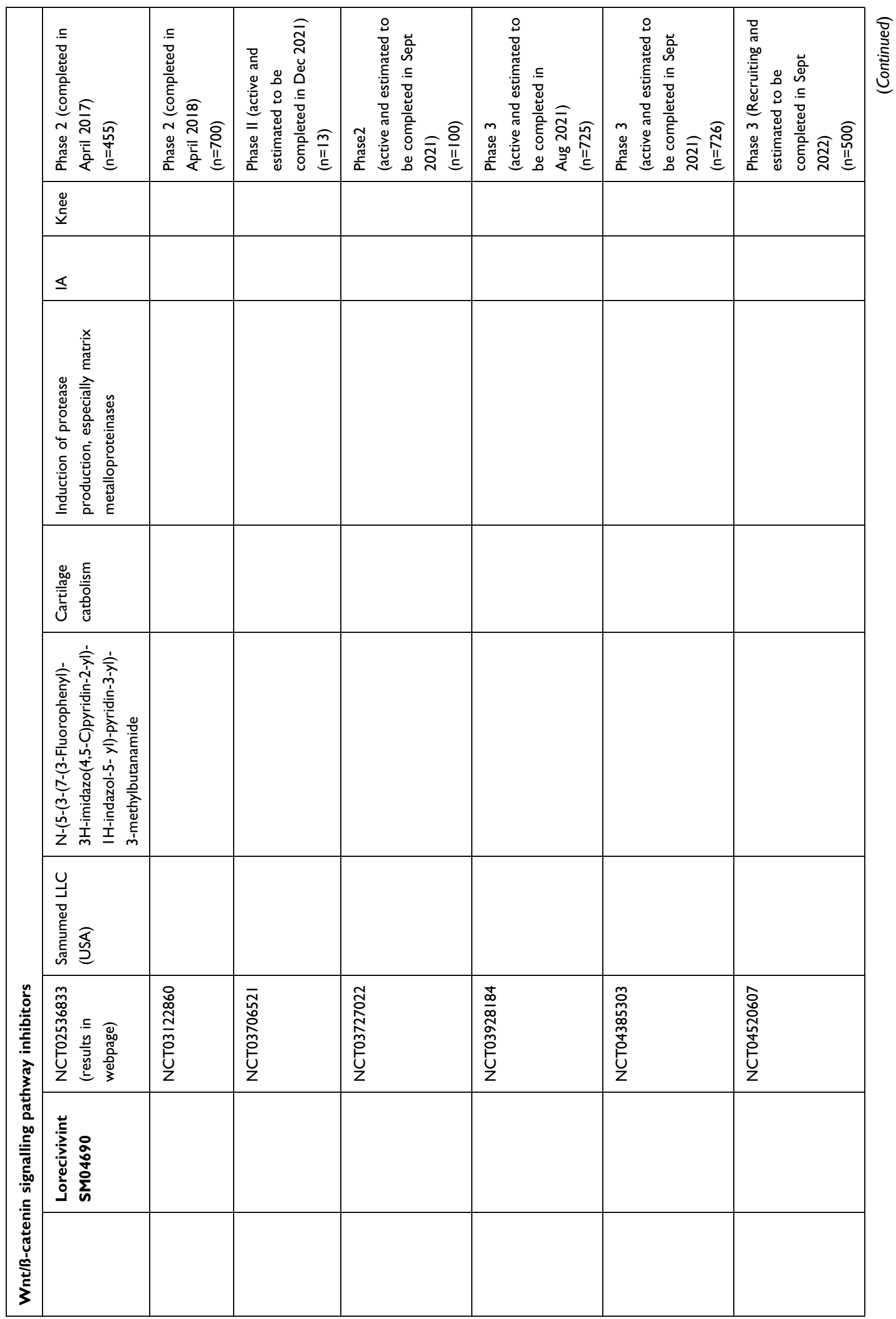




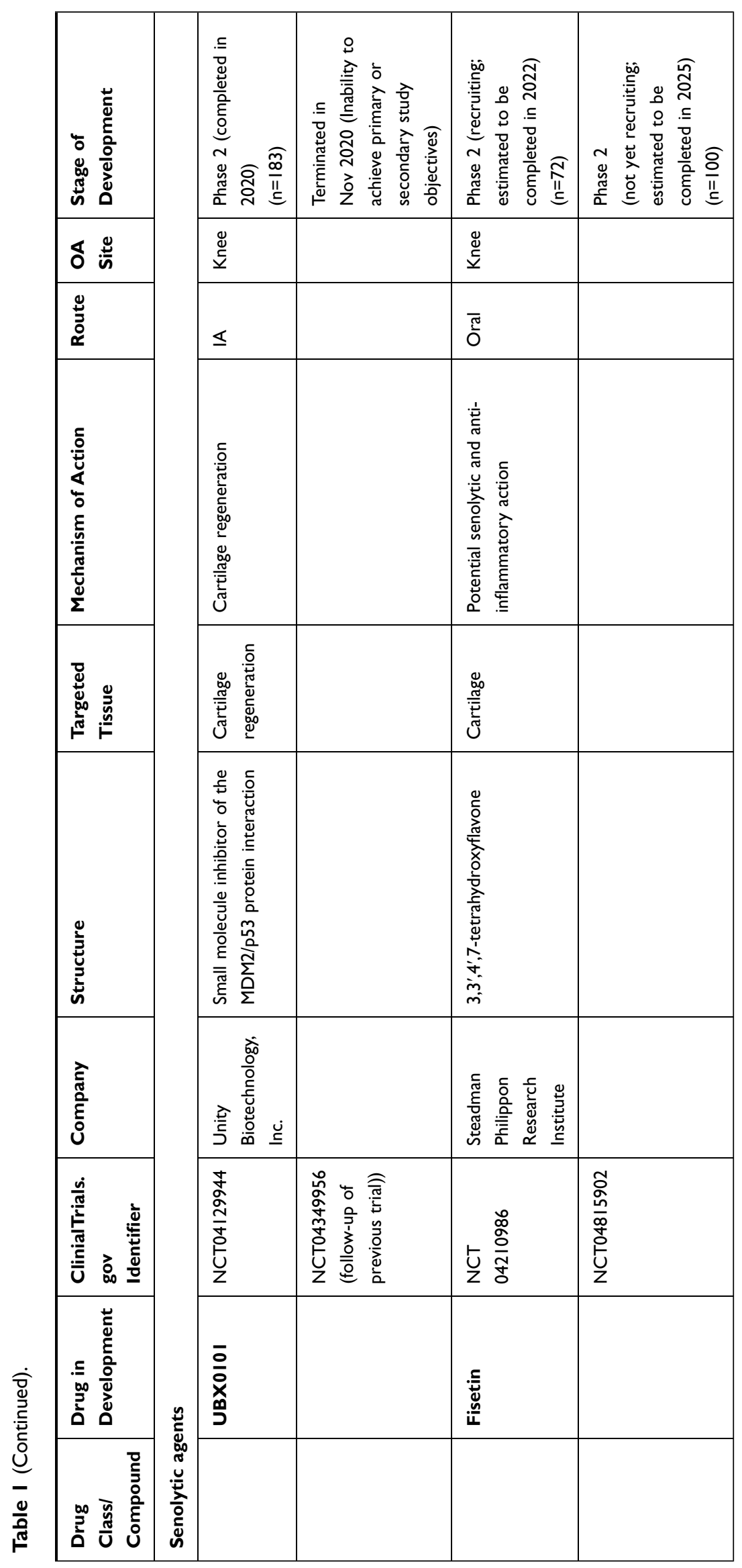


cartilage thickness [in mm (SD)] of central medial tibiofemoral compartment of the target knee via quantitative MRI was $-0.116(0.27)$ for the placebo group and -0.068 $(0.20),-0.097(0.27)$ and $0.085(0.22)$, for the low, medium and high dose, respectively. There was no statistically significant difference versus placebo in both MRI and clinical outcome measures. ${ }^{37}$ Another ADAMTS5targeting agent, M6495 an anti-ADAMTS5 Nanobody (Ablynx), showed an acceptable safety profile and dosedependent effects in a phase- 1 study. ${ }^{38}$

\section{Fibroblast Growth Factor 18}

Sprifermin is a recombinant human fibroblast growth factor 18 (FGF18) which binds to fibroblast growth factor receptor-3 (FGFR-3) in cartilage. ${ }^{39}$ It stimulates the proliferation of articular chondrocytes and induces hyaline extracellular matrix synthesis in rat OA models. ${ }^{40}$ At the cellular level, intermittent administration may transiently promote an anabolic effect, while continuous administration may stimulate other signalling pathways, leading to a weaker effect. $^{41}$

Lohmander et al reported in 2014 that intra-articular (IA) sprifermin administration did not improve medial tibiofemoral cartilage-thickness over 12 months quantified by MRI $(n=168)$ possibly as follow-ups were too short for detection of the full disease-modifying effect of treatment. $^{39}$ However, a significant dose-dependent response was detected in total and lateral tibiofemoral cartilage-thickness and radiographic JSW over 12 months. The authors speculated that the dynamic loading implicated in predominantly medial tibiofemoral involvement seems to impede attempts to prevent cartilage loss or regenerate cartilage tissue. Sprifermin had no major local or systemic adverse events compared with placebo. Conference abstracts published in 2015 and 2016 reported the structure-modifying effects on cartilage thickness and bone marrow lesions (BMLs) on MRI on 12-month follow-up, using post-hoc analyses of the same study. ${ }^{42,43}$

In another clinical trial in which Sprifermin was administered up to $300 \mu \mathrm{g}$ for advanced knee OA, it was reported in 2016 that no significant benefits were detected for cartilage outcomes on histology, synovitis, effusion, BMLs on MRI and JSW on X-ray. However, the study was underpowered as MRI was only available in 30 out of 52 patients and the follow-up period was only 24 weeks, which may be too short for capturing the structuremodifying effects. $^{44}$
In a 5-year, phase 2 dose-finding, multicenter randomized clinical trial [FGF18 Osteoarthritis Randomized Trial with administration of Repeated Doses (FORWARD) study], the effects of Sprifermin on changes in total femorotibial joint cartilage thickness $(n=549)$ on MRI was evaluated at 2-year follow-up (NCT01919164). Hochberg et al reported in 2019 that three once-weekly IA injection of $100 \mu \mathrm{g}$ sprifermin provided a significant improvement in total femorotibial joint cartilage thickness [0.05 mm (95\% CI, 0.03 to $0.07 \mathrm{~mm})$ ] for participants administered every 6 months and $[0.04 \mathrm{~mm}$ (95\% CI, 0.02 to $0.06 \mathrm{~mm})$ ] for participants administered every 12 months, compared with the placebo saline injection provided every 6 months $(-0.02 \mathrm{~mm}){ }^{45}$ No significant improvement in total WOMAC scores was detected, compared with placebo. The most frequently reported treatment-emergent adverse event was arthralgia and showed no difference from the placebo group (43\%). An exploratory analysis of the same study at 3 year-follow-up $(n=442)$ reveals significant differences $(0.05 \mathrm{~mm}[95 \%$ CI, $0.03-0.07 \mathrm{~mm}]$ ) in total femorotibial joint cartilage thickness over MRI between Sprifermin (100 $\mu \mathrm{g}$ of Sprifermin every 6 months) and placebo (saline every 6 months). ${ }^{45}$ However, the clinical significance of a $0.05-$ $\mathrm{mm}$ increase of cartilage thickness in this study remains unclear in terms of reducing risk for knee replacement, delaying time towards knee replacement, or both. ${ }^{46}$ No significant change in total WOMAC scores in this study may be attributed to using intra-articular saline injections as a control since the IA saline injection may act as an active placebo, ${ }^{47}$ masking symptomatic benefits. In addition, a large number of patients with low baseline pain and/or high baseline cartilage thickness may result in a potential "floor effect" on symptoms as $32 \%$ of this study had $<40 / 100$ points on WOMAC pain score at baseline and $50 \%$ had medial minimum joint space width (mJSW) $>4.0 \mathrm{~mm}$ on baseline X-rays. Therefore, analysis of a more selective subgroup, featuring baseline characteristics associated with rapid structural and symptomatic OA progression should be investigated. In a 2019 ACR conference abstract, it was reported that in a "subgroup at risk" ( $n=161)$ of structural and symptomatic progression with a baseline medial or lateral mJSW between 1.5 and $3.5 \mathrm{~mm}$ and WOMAC pain score of 40-90 out of 100, WOMAC pain was significantly improved on 3 year follow-up $[-8.8(-22.4,4.9)]$ in the group administered with the $100 \mu \mathrm{g}$ Sprifermin $(\mathrm{n}=34)$ compared with the placebo $(n=33)^{48}$ suggesting that, in this subgroup, the drug effect 
reaches the absolute minimal clinically important improvement for the WOMAC pain subscore which ranges 6-9. ${ }^{49}$

In a recent 2020 paper using a post-hoc analysis of the same data from the FORWARD study, thinning/thickening scores and ordered values of femorotibial cartilage thickness change on MRI over 24 months were analyzed by applying location-independent (ie not region-specific) analysis methodology in the knee joint. ${ }^{50}$ With administration of $100 \mu \mathrm{g}$ Sprifermin every 6 months cartilage thickening is more than double [ $856 \mu \mathrm{m}$ (717 to 996$)$ vs $356 \mu \mathrm{m}$ (313 to 398$)]$ and cartilage thinning almost reduced to $[-432 \mu \mathrm{m}$ ( -521 to -343$)$ vs $-335 \mu \mathrm{m}(-381$ to -288$)]$ that in healthy reference subjects from the Osteoarthritis Initiative dataset $(\mathrm{n}=82)$. The authors concluded that the finding supported the evidence of substantial structure-protective action of Sprifermin. However, as this is a post-hoc analysis, further study will be required to confirm its structure-modifying effect.

\section{Wnt Signalling Inhibitors}

At a molecular level, the regulation of Wnt signalling determines osteoblast and chondrocyte lineage specification and their homeostasis. ${ }^{51}$ Increased Wnt signaling predisposes MSCs to an osteogenic lineage fate and induces generation of metalloproteinases which can cause cartilage degradation in OA. ${ }^{52}$ Increased expression and activation of the Wnt pathway in articular cartilage chondrocytes in OA similarly promotes cartilage degradation, while elevated Wnt signalling in subchondral bone enhances bone formation and sclerosis. ${ }^{53-55}$ Therefore, pharmacological modulation of Wnt signaling might have potential benefits in repairing osteochondral dysregulation detected in OA disease process. Moreover, increased Wnt signaling in the synovium may potently lead to the OA progression via increased production of MMPs as well as activation of osteoclast differentiation and enhanced subchondral bone turnover. ${ }^{56,57}$

Lorecivivint (SM04690) is a small-molecule CLK/ DYRK1A inhibitor that blocks Wnt signalling at the transcriptional level. ${ }^{58}$ It showed induction of chondrogenesis and reduction in cartilage degradation in preclinical studies. ${ }^{58-60}$ In a 52-week, multicenter, phase-2 trial $(\mathrm{n}=455)$ (NCT02536833), the primary end point, a significant improvement in the WOMAC pain score compared with placebo at week 13, was not met, compared with IA placebo saline injection, However, at 52week follow-up, intra-articular administration of $0.07 \mathrm{mg}$ demonstrated a significant benefit in pain and functional scores [between-group difference versus placebo, -8.73 , 95\% CI $(-17.44,-0.03)$ and $-10.26,95 \%$ CI $(-19.82$, $-0.69)$ ], as well as improvement in mJSW on X-rays [between-group difference versus placebo, $+0.39 \mathrm{~mm}$, $95 \%$ CI $(0.06,0.72)]$ in patients with unilateral knee OA. Serious adverse events were reported in $17(3.7 \%)$ patients. $^{61}$ The most common SAEs included infections and cardiac disorders and were deemed unrelated to the study drug by the investigators. ${ }^{62}$

Another phase-2 trial evaluated in 700 patients for 24 weeks was completed (NCT03122860) where the $0.07 \mathrm{mg}$ lorecivivint treatment group demonstrated more favorable reductions in both WOMAC indices as compared with placebo. ${ }^{63}$ Recently, the investigators reported the safety data after the combined analysis of the two trials, which included 848 Lorecivivint-treated and 360 control subjects in total. The incidence of adverse effects or serious adverse effects was similar in treatment $(41.3 \%$ and $2.4 \%$ ) and control groups (38.3\% and $1.1 \%$ ), respectively. The most commonly reported $\mathrm{AE}$ in both groups was arthralgia $(7.6 \%$ vs $7.2 \%){ }^{64}$ Two small phase-2 (NCT03727022, NCT03706521) and three phase-3 (NCT03928184, NCT04385303, NCT04520607) trials are still active.

\section{Transforming Growth Factor- $\beta$}

Transforming growth factor- $\beta$ (TGF- $\beta$ ) induces extracellular matrix protein synthesis and modulates cartilage development. A variety of TGF- $\beta$ signalling pathways are crucial for early cartilage growth, maintaining cartilage homeostasis in later life and may also possess antiinflammatory and immunosuppressive properties. ${ }^{65}$ Impaired TGF- $\beta$ function in cartilage might be related to an increased susceptibility to OA. ${ }^{66}$ However, the biological effect of TGF- $\beta$ is under complex control, and may switch from being protective in normal joints to detrimental in OA as a result of changes in the predominant cellsurface receptors and intra-cellular signalling pathways in various joint tissues (cartilage, bone, synovium). ${ }^{67}$ In addition, osteocyte TGF- $\beta$ signaling could regulate the osteogenic and osteoclastic activity of mesenchymal stem cells and may be associated with the remodeling of subchondral bone in advanced OA. ${ }^{68}$

TissueGene-C (TG-C) uses a cell-mediated cytokine gene therapy approach and includes non-irradiated allogeneic human chondrocytes and irradiated allogeneic human GP2-293 cells in a ratio of 3:1, retrovirally transduced to promote TGF-betal transcription (hChonJb\#7 
cells). ${ }^{69-71} \mathrm{~A}$ recent study reported as a possible mechanism of action that TG-C induced an M2 macrophagedominant pro-anabolic micro-environment in a rat model, thereby providing a beneficial effect on cartilage regeneration. ${ }^{72}$ At one-year follow-up after a single IA administration, there were significant improvements in pain, sports activities and quality of life but structuremodifying effects on the cartilage were insignificant $(\mathrm{n}=156) .^{73}$ In a phase- 2 trial (NCT01221441) including 57 patients in the treatment group and 29 patients in the placebo group, the TG-C administration caused less progression (47.9\% vs 34.6\%; adjusted RR 0.7, 95\% CI $0.5-$ 1.1) of cartilage damage than placebo over 12-months. ${ }^{69}$ In a phase-3 trial (NCT02072070) which included 163 patients, symptomatic benefit was detected. ${ }^{74}$

The two pivotal phase-3 trials (NCT03203330, NCT03291470) had been on hold in April 2019 while the regulators were investigating chemistry, manufacturing, and control issues related with the potential mislabeling of ingredients. ${ }^{75}$ This clinical hold was lifted in April 2020, and trial enrollments have been reinitiated later in $2020 .^{76}$ Recently, analysis of the safety data from an observational long-term safety follow-up trial showed that there is no evidence to suggest that injection of TG-C was associated with increased risk of cancer nor generated any long-term safety concerns over an average 10 years. ${ }^{71}$

\section{Senolytic Therapies}

Senescence is characterized mainly by altered responses to cellular stress and proliferation arrest of cells. ${ }^{77}$ Senescent cells (SnCs) are a newly implicated factor in the OA pathogenic process $^{78}$ by promoting pathological agerelated deterioration via the production of proinflammatory cytokines, chemokines, extracellular proteases, and growth factors (termed the senescence-associated secretory phenotype (SASP) $)^{79}$ and altering the function of neighbouring cells (termed secondary or paracrine senescence). ${ }^{80}$ Therefore, senotherapeutics which are directed at SnCs are an emerging therapy for treating diseases related to ageing. Senotherapeutics can be classified into of 3 types: 1) senolytics which kill and destroy SnCs selectively; 2) senomorphics which modulate or even reverse the phenotype of SnCs to those of young cells by blocking SASP; 3) senoinflammation, the immune system-mediated clearance of SnCs. ${ }^{81}$ Several senolytic pharmaceutical drugs such as Fisetin and UBX0101 are emerging.

Fisetin is a polyphenol extracted from fruits and vegetables and shows potential senolytic and anti-inflammatory

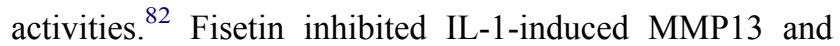
ADAMTS5 expression in human OA chondrocytes in vitro, and reduced cartilage damage along with subchondral bone thickening and synovitis in a mouse OA model induced by destabilization of the medial meniscus (DMM). ${ }^{83}$ Two phase-2 clinical trials (NCT 04210986, NCT04815902) are under investigation in patients with knee OA and estimated to be completed in 2022 and 2025, respectively.

UBX0101 is a small molecule inhibitor of the MDM2/ p53 protein interaction, which possesses a potent senolytic candidate. In a preclinical study, UBX0101 improved chondrogenesis in human OA tissue in vitro, and in an anterior cruciate ligament transection (ACLT) OA model in mice UBX0101 attenuated SnCs by stimulating apoptosis, and reduced cartilage damage and joint pain. ${ }^{84}$ The amount $\mathrm{SnCs}$ in human OA synovial tissues positively correlated with knee pain, disease severity and synovitis severity. ${ }^{85}$ A phase-1 study $(n=48)$ revealed that a single intra-articular injection of UBX0101 at different doses up to $4 \mathrm{mg}$ had a favorable safety profile and dose-dependent, clinically meaningful improvements in pain on Numeric Rating Scale (0-10) [-3.95 (95\% CI, -4.74, -3.16)] and WOMAC function $[-1.05(95 \% \mathrm{CI},-1.36,-0.74)]$ compared with placebo injection. Recently, UNITY Biotechnology announced 12-week data from UBX0101 Phase-2 Clinical Study (NCT04129944) which did not detect a significant change in pain and function in 183 patients with painful knee OA. ${ }^{86}$ A follow-up observational study of the previous trial (NCT04349956) was terminated in November 2020 due to failure to meet the trial outcomes.

\section{Bone-Driven Endotype}

Subchondral change in OA involves an uncoupled remodelling process, which is characterized by both increased osteoblast activation and bone formation but simultaneously macrophage infiltration and osteoclast formation. ${ }^{87}$ Activation of osteoclasts can result in pain genesis through developing acidic conditions at the osteochondral junction, thereby activating acid-sensing receptors of sensory neurons. ${ }^{88,89}$ Subchondral bone also undergoes remarkable alterations in both composition and structural organization, leading to adverse effects on the overlying articular cartilage. ${ }^{90}$ Therefore, targeting the pathways that modify subchondral bone turnover is an attractive option for DMOAD research. ${ }^{89}$ The 
pharmaceutical drugs in phase 2 and 3 stages of development for bone-driven endotype are summarized in Table 2 .

\section{Cathepsin K Inhibitor}

Cathepsin $\mathrm{K}$ is a cysteine protease which induces bone resorption and cartilage damage through the breakdown of key bone matrix proteins. ${ }^{91,92}$ Cathepsin K knock out mice had attenuated cartilage damage in OA induced by DMM, and inhibition of Cathepsin $\mathrm{K}$ in rabbits by daily oral dosing with L-006235 reduced cartilage damage and subchondral bone remodelling in an ACLT model of OA. ${ }^{93,94}$

MIV-711 is a selective cathepsin $\mathrm{K}$ inhibitor, and in a 6-month phase 2 clinical trial (NCT02705625) $(n=244)$, significantly reduced femoral bone disease progression and reduced cartilage loss, although there was no improvement in pain outcome. ${ }^{95}$ Infrequent musculoskeletal symptoms, infections and rashes were reported. A further 6-month open-level extension study showed the maintenance of structural benefit with symptomatic improvement $(n=50){ }^{96}$ However, as most of the participants in the extension substudy were selected because their symptoms did not worsen, a treatment benefit may be due to positive selection bias. ${ }^{95}$

\section{Parathyroid Hormone (PTH)}

Recombinant human PTH, teriparatide, is a 1-34 aminoacid fragment acquired from human PTH). Its anabolic action on bone production is used for osteoporosis management. In OA, it exhibits the ability to maintain articular cartilage health, ${ }^{97}$ stimulate the synthesis of extracellular matrix and induce chondrocyte proliferation in pre-clinical injury-induced OA models. ${ }^{98}$ PTH can increase subchondral bone mineral density, which could exert a negative effect on OA progression. In this sense, PTH could be an excellent drug in OA patients with osteoporosis and low subchondral sclerosis. ${ }^{99}$ Additionally, intermittent parathyroid hormone treatment attenuates $O A$ pain in a DMM model, in association with inhibiting subchondral sensory innervation, subchondral bone deterioration, and articular cartilage degeneration. ${ }^{100} \mathrm{~A}$ phase-2 study is currently ongoing to evaluate the efficacy of PTH in knee OA participants (NCT03072147).

\section{Matrix Extracellular Phosphoglycoprotein (MEPE)}

TPX-100 is a novel 23-amino-acid peptide derived from MEPE, a member of the Small Integrin-Binding Ligand, N-linked Glycoprotein (SIBLING) protein family, involved in subchondral bone remodeling. ${ }^{101}$ TPX-100 provided symptomatic improvements in patellofemoral OA knees administered with 4 weekly $200 \mathrm{mg}$ injections compared with placebo injection in the contralateral knees $(n=93)$, but only $14 \%$ of knees showed changes in cartilage thickness/volume measured on MRI over 12 months with no evidence of structural modification. No drugrelated SAEs occurred in this study. ${ }^{102}$ Another 2020 OARSI conference abstract reported a statistically significant decrease in pathologic bone shape change in the femur at both 6 and 12 months using 3D femoral bone shape change. ${ }^{103}$

\section{Antiresorptive Drugs: Bisphosphonates and Denosumab}

Antiresorptive drugs have shown reduction in bone remodeling and improvement in trabecular microarchitecture and bone mineralization. In clinical trials investigating the structure-modifying effects of bisphosphonates (alendronate, risedronate, zoledronic acid), the results are inconsistent across the studies and their outcomes presented a great heterogeneity. ${ }^{17,104}$ In a recent systematic review including preclinical studies $(n=26)$ over the past two decades (2000-2020), these drugs showed better chondroprotective effects at high doses with a dosedependent manner as well as depending on the timing of treatment initiation in relation to $\mathrm{OA}$ stage (timedependency). ${ }^{105}$ Therefore, these agents may still be of potential benefits in certain OA endotypes with high rates of subchondral bone turnover. This phenotypedependency has been demonstrated in pre-clinical research, where bisphosphonates are differentially effective in reducing pain and not only bone but also cartilage pathology in OA models with high versus low bone turnover. ${ }^{106-109}$ Recently, clodronate $(\mathrm{n}=74)^{110}$ and neridronate $(n=64)^{111}$ have been successfully used for the treatment of knee and hand OA, with an interesting efficacy on BMLs, although the sample sizes are small. An individual patient data meta-analysis for examining their efficacy in specific knee OA subtypes is still ongoing. ${ }^{12}$

In a multicentre, randomised controlled trial involving knee OA patients with significant knee pain and MRIdetected BMLs ( $\mathrm{n}=223), 2$ annual infusions with $5 \mathrm{mg}$ of zoledronic acid (the most potent of all bisphosphonates) did not significantly reduce cartilage volume loss, knee pain or BML size although the study was designed for detecting effects on the bone-driven subgroup with BMLs 


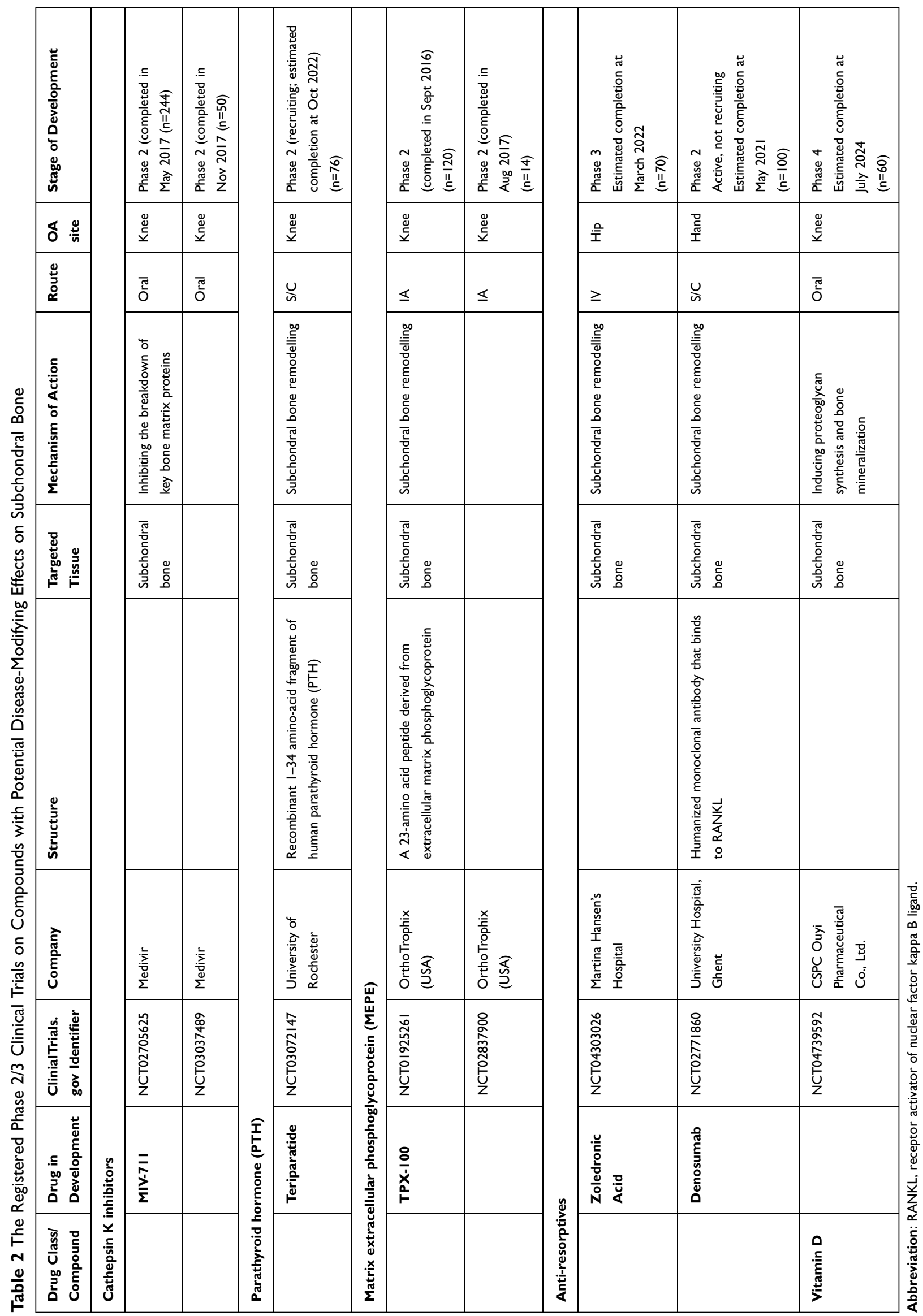


which may likely have potential benefits from this therapy. ${ }^{113}$ It was noted that more knee replacement procedures were performed in the zoledronic acid group compared with the placebo group ( $9 \%$ vs $2 \%$ ) in contrast with other population-based studies. ${ }^{114,115}$

Another study involving Osteoarthritis Initiative (OAI) female participants $(n=346)$ showed that bisphosphonate therapy may be protective of radiographic knee OA progression in non-overweight patients with early-stage OA. ${ }^{116}$ Currently, a Phase 3 study (NCT04303026) to examine its effects in hip $\mathrm{OA}$ is ongoing. A phase 2 study examining the effects of another anti-resorptive, denosumab, in hand OA is expected to finish in 2021 (NCT02771860).

\section{Vitamin D}

Vitamin D has a direct impact on cartilage by inducing proteoglycan synthesis in mature chondrocytes, ${ }^{117}$ and enhances chondrocyte viability and reduces their inflammatory cytokine synthesis through activating AMPK/mTOR and autophagy. ${ }^{118}$ Active vitamin $\mathrm{D}$ administration reduced cartilage degradation and inflammation in models of OA in mice and rats induced by meniscal injury/meniscectomy and ACLT. ${ }^{118-120}$ Out of two recently published systematic reviews, one review showed the association of vitamin $\mathrm{D}$ deficiency with knee $\mathrm{OA}$ in patients but inconsistent evidence for its role in the prevention of incidence and progression of radiographic $\mathrm{OA},{ }^{121}$ while the other argued that inconsistent results may be attributed to factors such as severity of knee OA, baseline level of serum vitamin D, duration of treatment, and vitamin $\mathrm{D}$ dosages. ${ }^{122}$ There is a need for multicentric and well-conducted randomized studies using larger samples to determine its efficacy. A small Phase 4 clinical trial is currently active (NCT04739592).

\section{Synovitis-Driven Endotype}

Synovial inflammation (synovitis) is an important contributing factor to the OA pathogenesis through increased local production of pro-inflammatory cytokines, chemokines, and mediators of joint tissue damage $e^{123,124}$ which may be amenable to a range of anti-inflammatory drugs commonly used in inflammatory rheumatic diseases. The pharmaceutical drugs in phase 2 and 3 stages of development for inflammation-driven endotype are summarized in Table 3.

\section{Diacerein}

Diacerein is a purified anthraquinone derivative. It involves an inhibitory action on IL- $1 \beta$ and its signalling pathway, possesses an anticatabolic effect on OA tissues and reduces generation of metalloproteases. ${ }^{125}$ In animal models of OA (sheep meniscectomy, canine ACLT, rabbit ACLT and partial meniscectomy) diacerein has generally shown limited long-term effect on cartilage composition or pathology, but some evidence of reducing synovitis. ${ }^{126-129}$ In a 2014 Cochrane review, the authors concluded that diacerein demonstrated only a minimal symptomatic improvement in patients with unclear benefits in JSW on X-rays, compared with placebo. Diarrhoea was the main adverse event with an absolute difference of $26 \% .{ }^{130}$

The EMA's Pharmacovigilance Risk Assessment Committee suspended diacerein across Europe in 2013 due to its harms overweighing benefits, ${ }^{131}$ and then reevaluated the drug in 2014, suggesting that 'it remain available with restrictions to limit risks of severe diarrhoea and hepatotoxicity'. ${ }^{132}$ In 2016, the European Society for Clinical and Economic Aspects of Osteoporosis and Osteoarthritis (ESCEO) reported that diacerein had efficacy similar to that of NSAIDs with slower onset of action, suggesting that it might have some benefits for patients with contraindication to NSAID. ${ }^{133}$

Recently, results of a phase-3 clinical trial (NCT02688400) were reported where the authors explored the comparative efficacy and safety of diacerein vs celecoxib in patients with moderate and severe knee OA using a non-inferiority trial design [(6-months of diacerein $50 \mathrm{mg}$ once daily for 1 month and twice daily thereafter $(n=187)$, or celecoxib $200 \mathrm{mg}$ once daily $(\mathrm{n}=193)]$. Diacerein was non-inferior to celecoxib in reducing pain, stiffness, or functional limitations. The diacerein group had a higher number of emergent AEs (26.3\%) compared with the celecoxib group (17.4\%), mainly due to higher diarrhoea events ( $10.2 \%$ vs $3.7 \%)$. One patient in the diacerein group had three SAEs (abdominal pain, elevated transaminase and gamma-glutamyl transferase, collectively suggestive of hepatitis) which resolved spontaneously following drug withdrawal. ${ }^{134}$

\section{Anti-Inflammatory Agents (Targeting IL-I, TNF- $\alpha$ )}

In in vitro and in vivo preclinical studies, interleukin-1 (IL-1), tumor necrosis factor- $\alpha$ (TNF- $\alpha$ ), IL-6, IL-15, IL-17, and IL18 exhibit pro-inflammatory actions, leading to the initiation and progression of cartilage damage and joint inflammation. 


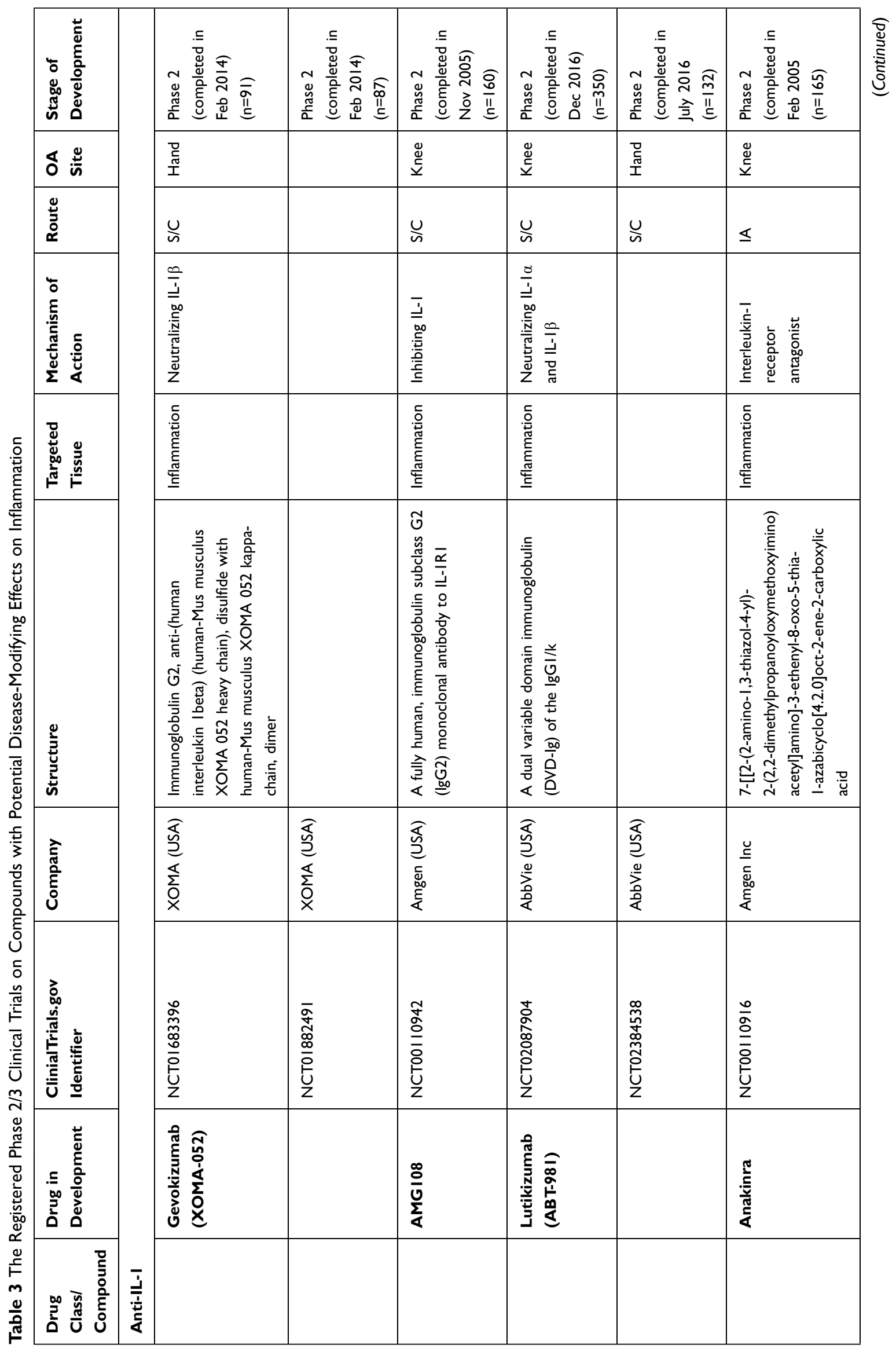




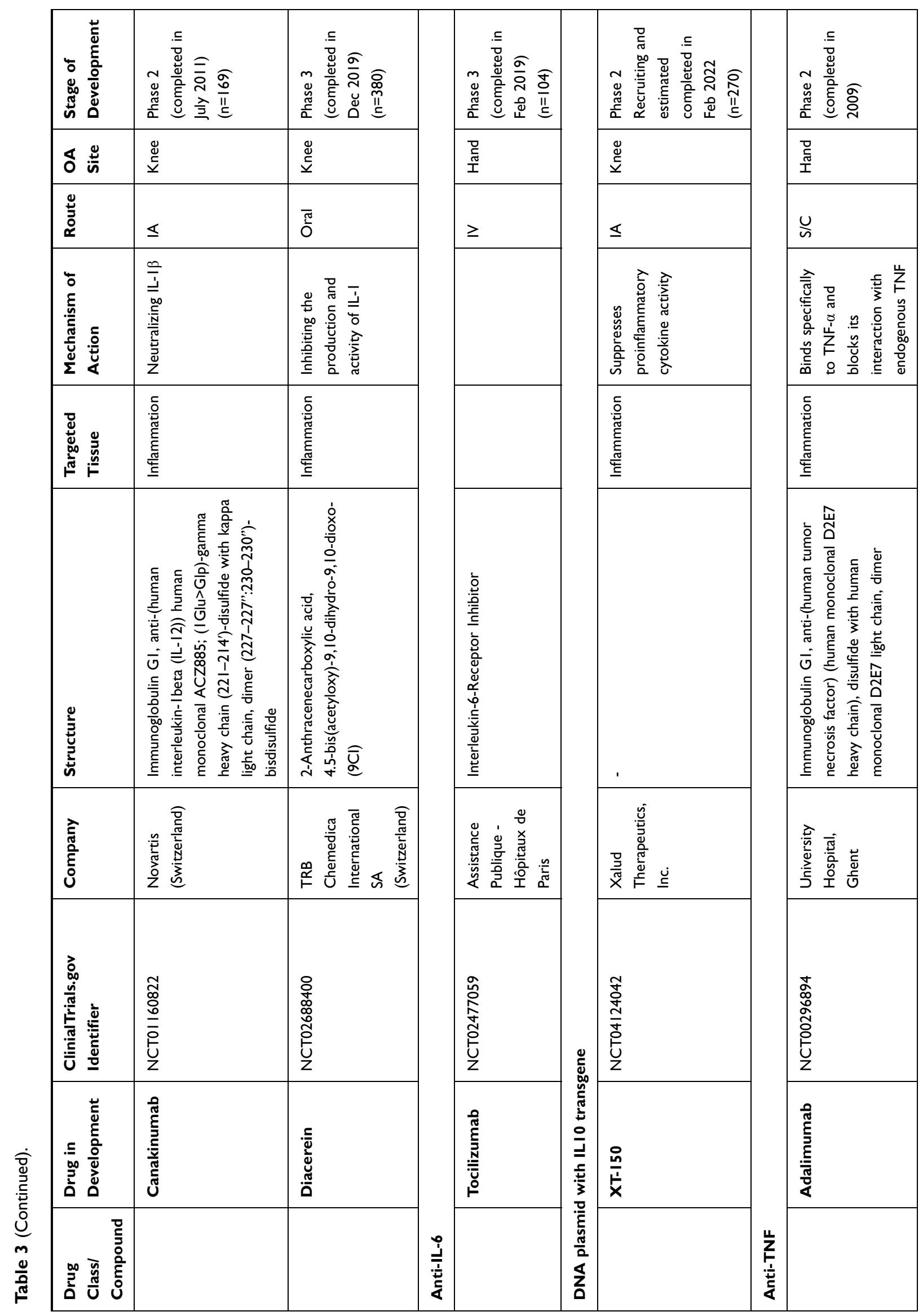




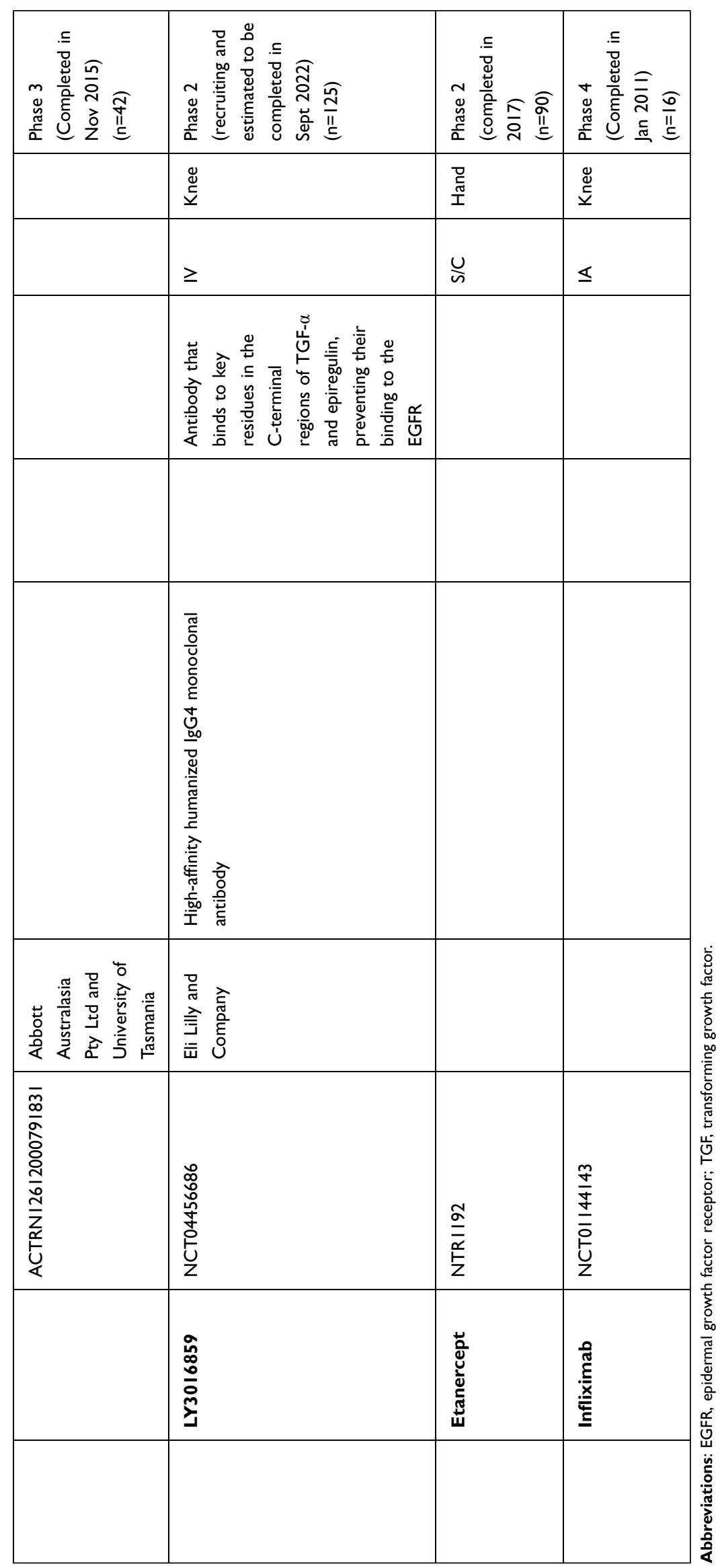


So far, IL-1 $\beta$ and TNF- $\alpha$ have been the most extensively studied cytokines in pre-clinical research. ${ }^{135,136}$ Despite this favorable evidence in animal OA models, most clinical trials investigating the disease-modifying effects demonstrated by inhibitors of IL- 1 and TNF- $\alpha$ in OA patients failed to meet the primary and secondary endpoints such as in cases of Gevokizumab (XOMA-052), ${ }^{137}$ AMG108, ${ }^{138}$ Lutikizumab $\left(\right.$ ABT-981) ${ }^{139,140}$ anakinra, ${ }^{141}$ adalimumab ${ }^{142-144}$ and etanercept. ${ }^{145}$ In a meta-analysis evaluating the efficacy of disease-modifying anti-rheumatic drugs in OA, neither IL1inhibitors nor TNF-inhibitors possess symptomatic benefits irrespective of the joint site affected or the inflammatory phenotype (erosive or non-erosive OA). ${ }^{146}$

These failed trial results may suggest the implication of a more complicated interaction among various cytokines in the OA pathogenic process. One of the reasons for failure may be that the clinical trials were designed to detect an effect on symptoms rather than on joint structure, which is conversely the main outcome evaluated in preclinical studies, or that they are underpowered or have not followed participants for long enough to find meaningful structural effects such as proposed in the recent CANTOS trial. ${ }^{147}$ In a recent exploratory analysis of the CANTOS trial involving patients with elevated high-sensitivity C-reactive protein (hs-CRP) levels $\geq 2 \mathrm{mg} / \mathrm{L}$ and a history of myocardial infarction $(\mathrm{n}=10061)$, IL-1 inhibition using canakinumab may render a substantial reduction of THR/TKR rates as well as OArelated symptoms on an averaged 3.7 years follow-up. ${ }^{147}$ Although the study had some positives such as a large sample size and long-term follow-up, it was not primarily designed to investigate the DMOAD efficacy of canakinumab and many relevant OA outcomes were missing, necessitating further confirmatory studies.

\section{Tocilizumab}

IL-6 can increase the risk of radiographic OA and associated with knee cartilage damage, ${ }^{148}$ suggesting the potential role of low-level inflammation in the pathogenesis of OA. IL-6R blockage with tocilizumab contributes to cartilage preservation and increases bone volume in a mouse model of ischemic osteonecrosis, ${ }^{149}$ and reduced cartilage lesions, osteophyte formation and synovitis in DMM-induced OA in mice. ${ }^{150}$ However, male IL-6 knock out mice have increased cartilage damage and agerelated OA. ${ }^{151}$ In local joint tissues, IL-6 classic signaling produces structure-protective effects, while trans-signaling leads to catabolic effects. ${ }^{152}$ This finding might suggest that selective inhibition of IL- 6 trans-signaling could be a superior treatment strategy as this may inhibit deleterious IL-6 effects in OA, while maintaining protective IL-6 signaling via the classic pathway. ${ }^{153}$ Recently, in a phase-3 trial evaluating the efficacy of tocilizumab in hand OA for 12 weeks $(n=104)$, it revealed no more effectiveness than placebo for pain relief $(-7.9$ vs -9.9 on VAS score in the tocilizumab and placebo groups). ${ }^{154}$

\section{XT- 150}

Interleukin-10 (IL-10) is an anti-inflammatory cytokine that potently and broadly suppresses proinflammatory cytokine activity. It also possesses chondroprotective effects, via reduced production of matrix metalloproteases ${ }^{155}$ as well as inhibition of chondrocyte apoptosis. ${ }^{156}$ Therefore, IL-10 could have potential benefits in OA management, both for pain improvement and suppression of the cartilage-damaging processes. Currently, there is a phase- 2 clinical trial evaluating the safety and efficacy of a single injection of XT-150 (a plasmid DNA with a variant of human IL-10 transgene) in patients with knee OA (NCT04124042), and it is estimated to be complete in 2022 .

\section{Perspectives}

In this section, we briefly put forward the reasons for failures in OA clinical trials and possible steps to overcome these barriers (Figure 2).

\section{Regulatory Approval for DMOADs}

The drug will be required to demonstrate symptomatic benefits (pain and/or function) coupled with structural modifications to meet regulatory requirements as a disease-modifying agent. ${ }^{19,20}$ To date, no agent has been approved by the regulatory agencies. ${ }^{17}$ Some argue that the improvements in structural change (in the absence of any meaningful symptomatic benefits) should be a meaningful target for approval, in and of itself. However, this is unlikely to meet consumers needs as their primary reason for clinical presentation relates to symptomatic complaints. ${ }^{30}$

On the other hand, OA is a slowly progressive disease and only $14 \%$ of patients with incident OA have measurable disease progression over a 1-year period (Figure 2). ${ }^{157}$ Therefore, structure-modifying effects using targeted therapy would be optimal to delay or even avoid disease worsening and joint replacement. In OA, symptom-structure discordance is often described. ${ }^{158}$ Analysis of data from the Osteoarthritis Initiative revealed that changes in bone structure over 2 years do not translate into pain worsening 


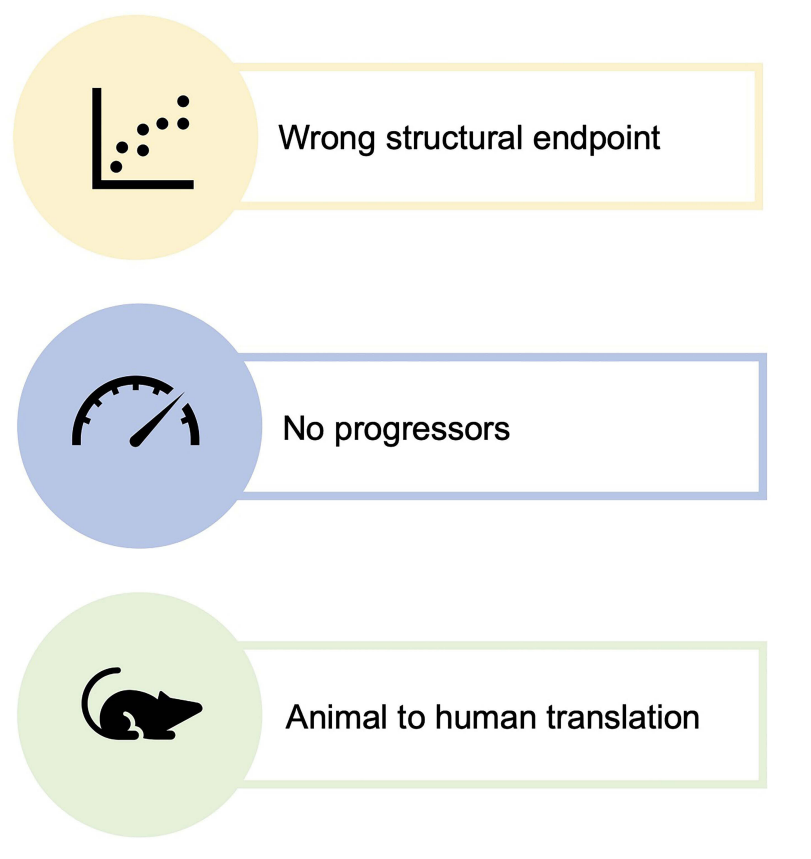

Figure 2 Reasons for DMOAD trial failures.

until 4 years, ${ }^{159}$ suggesting that a structure-modifying drug may need longer follow-up to detect symptomatic benefit. In addition, a variety of disease outcomes using different OA subtypes (genotypes, phenotypes and endotypes) are needed to demonstrate the ability of a structure-modifying drug to directly predict for symptomatic benefits to overcome the regulatory hurdles. ${ }^{18}$

In addition, FDA's formal recognition of OA as a serious disease paves the way for using surrogate outcome measures for regulatory approval of DMOADs under accelerated approval regulations. However, two challenges need to be addressed: 1) selection/qualification of appropriate surrogate outcome measures, and 2) appropriate designs for postmarketing confirmatory studies. To overcome the first challenge, the Foundation for NIH (FNIH) OA Biomarkers Consortium initiative was established. ${ }^{160}$ For addressing the second challenge, Kraus et al proposed two major study design scenarios: 1) prospective trial continuation which continue all patients on initial drug allocation into the post-marketing approval trial until a failure threshold is achieved; and 2) separate post-marketing approval study which use different study population administered with active treatment only. ${ }^{161}$

\section{Imaging Tools Development}

The imaging standard in OA clinical trials has been radiographically measured $\mathrm{mJSW}$ which is notoriously

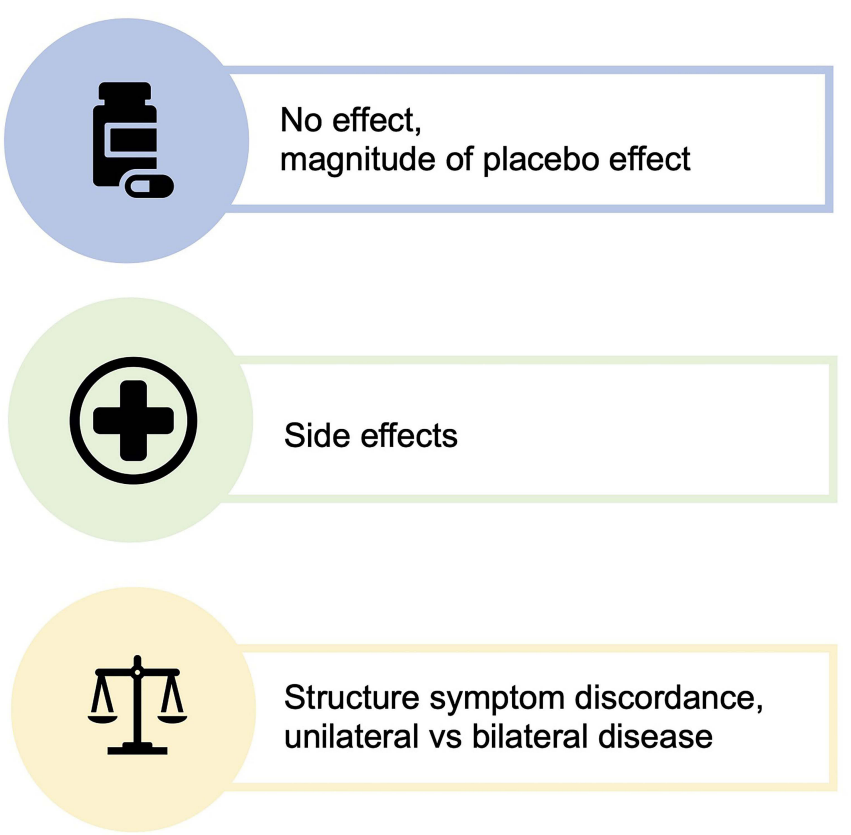

unresponsive to change as well as possessing several other drawbacks such as issues with alignment, positioning and assuming JSW as the composite contribution of changes in other structures in this heterogeneous OA with multiple-tissue involvement. ${ }^{162,163}$ Therefore, utilization of this insensitive-to-change measure may limit our opportunity to detect any modification in what oftentimes is a slow-moving disease.

In 2015 OARSI published recommendations related to the applications of knee imaging in knee OA trials to set standards and improve quality assurance. ${ }^{164}$ Although a range of different MRI approaches have been developed to evaluate changes in overall joint structure, ${ }^{165-167}$ further validation studies and evaluation of their clinimetrics are required to gain acceptance by regulatory authorities as a suitable surrogate endpoint which is the focus of the FNIH OA Biomarkers Consortium. ${ }^{160}$

In addition, the emergence of approved surrogate outcomes would allow pharmaceutical companies to examine the efficacy of the DMOADs in a shorter duration of clinical trials and reduce drug development costs. In this way, there is a possibility of instituting accelerated approval based on surrogate imaging endpoints and postmarketing approval studies to prove the longitudinal benefit-to-harm profile and the durability of the potential new therapies. $^{161}$ 


\section{Issues of Total Knee Replacement as an Endpoint}

In the study design for post-marketing approval which uses observational outcomes such as time-to-event of joint replacement surgery, considerable barriers exist in terms of need for large sample sizes due to low annual incidence rates (1.6-11.9\%), ${ }^{14}$ long study follow-ups $(>5$ years at least), ${ }^{46}$ and the impact of non-disease and other subjective factors on the outcome (ie, comorbidities and/or age of the patient, costs, insurance cover, etc.). ${ }^{168,169}$ There is a lack of universal consensus criteria for guiding patient recommendations regarding joint replacement surgery, leading to differences even among treatment centres within the same region. These issues need to be adequately addressed by study design. ${ }^{161}$ There is a need for developing a criteria set to define appropriateness for total knee replacement or a virtual total knee replacement. ${ }^{170}$

\section{Drug Delivery System for IA Therapies}

Instead of utilizing the systemic route of administration which may produce undesirable systemic toxicity and offtarget effects, many of the agents in the development pipeline are focused on an intra-articular route for drug delivery. This can also potentially enhance the local bioavailability, thereby maximizing therapeutic effects locally in the joint with a higher safety profile compared to systemic exposure. ${ }^{171}$ On the other hand, the marked placebo effect generated by local intraarticular administration is well-documented in the literature, ${ }^{172}$ making the assessment of symptom efficacy more challenging. ${ }^{30}$

Another issue related with the intra-articular therapy is that drugs have a short residence time within the joint. ${ }^{171,173}$ To overcome this barrier, a variety of drug delivery systems were proposed to prolong drug residence time while providing a stable concentration within the therapeutic window, leading to a reduction of side effects and better patient compliance. ${ }^{174}$ It remains unclear how long particular drugs have to remain in the joint for a meaningful symptomatic relief and/or structuremodification after an intra-articular administration. An ideal drug delivery system should comply with adequate disease modification, biocompatibility, and biodegradability while responding to its physiological environment. ${ }^{175}$

\section{Placebo Effects of IA Saline}

In the randomized clinical trials for IA drugs, saline is commonly used as the placebo in the control group.
A recent meta-analysis examining the effects of IA saline in 50 clinical trials $(n=4076)$ revealed significant improvement of pain severity on $0-100$ VAS up to 6 months [-13.4 (-21.7/-5.1)] and WOMAC function sub-score $[-10.1(-12.2,-8.0)]$. The pooled responder rate after saline injections using the OMERACT-OARSI criteria is $48 \%$ at 3 months and $56 \%$ at 6 months, ${ }^{47}$ challenging the concept of saline being a "mere" placebo. ${ }^{176}$ However, there is no evidence supporting hypotheses advocating the diseasemodifying role of saline injection. Future scientifically robust studies which examined the effects of sham injections compared with saline injections are required to shed new light on this issue.

The IA therapies show a considerably larger therapeutic effect after the adjustment for the effects of IA saline, suggesting an inappropriate underestimating of the true effect of the active medication. ${ }^{177}$ Further research is required to determine the underlying mechanisms and the factors influencing the placebo response and ways to overcome it. In addition, the mechanisms of pain genesis in $\mathrm{OA}$ are poorly understood and thought to involve a complex interaction among local pathological processes in the OA joint and neuronal mechanisms and alterations of pain processing (ie central sensitization, especially in advanced OA). ${ }^{178}$ Further studies should focus on the effects of these interactions on the outcomes in the placebo-controlled clinical trials. It is also necessary to strictly report in each clinical trial what placebo has been used as well as the presence or absence of any additional blinded clinical evaluator, even more, if considering clinical trials with intra-articular therapies.

\section{Combination Therapy}

As $\mathrm{OA}$ is a heterogeneous disease with a combination of different endotypes in varying degree at different stages of the disease process, a "one size fits all approach" using a single therapeutic agent targeting a single target within a single endotype may be unlikely to succeed in the management of OA. ${ }^{179}$ Therefore, as in the oncology therapeutic area, combinations of drugs targeting different hallmarks of OA pathogenic process should be considered. Further research examining the potential synergistic action of combining anabolic therapies with those that downregulate catabolic factors will be required.

\section{Personalized Medicine}

$\mathrm{OA}$ is well known for marked variations of disease expression, ${ }^{180}$ involves a variety of tissue pathologies as 
a whole joint disease ${ }^{16}$ and presents with different pathobiological manifestations, ${ }^{181}$ suggesting the potential value of personalised and precision medicine from the treatment perspective. Personalized medicine is used for treatment focusing on the patient based on their individual clinical characterization, considering the diversity of symptoms, severity, and genetic traits. ${ }^{182}$ In precision medicine, the molecular information maximizes the accuracy with which the patients are categorized and treated, typically applying large amounts of data for identification of patient subtypes which possess sharing specific relevant characteristics to predict diagnosis, progression, or treatment response, and to utilize appropriate therapeutic targets. ${ }^{183}$ The use of precision medicine in OA remains limited.

The implementation of private/ public initiatives, such as the Osteoarthritis Initiative, the FNIH biomarkers consortium, the European APPROACH ((Applied PublicPrivate Research enabling OsteoArthritis Clinical Headway)) project have contributed greatly to moving the field forward. Clinical phenotypes, endotypes, and molecular and imaging biomarkers are being identified, but the exact interplay among them and underlying mechanisms of each remain to be elucidated. ${ }^{24}$ While these biomarkers may have potential benefits in detecting those patients with the greatest risk for structural progression, their use still needs to be translated into more efficient clinical trial design and widespread clinical application. ${ }^{184}$

\section{Conclusion}

There remains an immense unmet need for effective and safe targeted interventions to inhibit both pain and disease progression. The complex overlapping interplay among the pathobiological OA processes and heterogeneity of clinical presentations of patients with OA, call for a universally accepted classification of phenotypes and endotypes for developing targeted disease-modifying therapy and providing the appropriate treatment in clinical setting. Although challenges exist towards the eventual management of OA by applying the concepts of personalized and precision medicine, the lessons learned through failed clinical trials, the ongoing developments of more advanced imaging and sophisticated biomarkers tools and effective drug delivery systems are leading to substantial progress in our field.

\section{Acknowledgments}

WMO is supported by the Presidential Scholarship of Myanmar for his PhD course. DJH is supported by the
NHMRC Investigator Grant. VD is supported by a University of Sydney Postgraduate Award scholarship.

\section{Disclosure}

DJH provides consulting advice on scientific advisory boards for Pfizer, Lilly, TLCBio, Novartis, Tissuegene, Biobone. CL has provided consulting advice for Merck Serono and Galapagos Pharmaceuticals, and receives research funding from numerous pharmaceutical companies (Fidia Farmaceutici, Inter-K Peptide Therapeutics Ltd, Taisho Pharmaceutical Co. Ltd, Concentric Analgesics Inc, Cynata Therapeutics, CEVA Animal Health, Regeneus) through specific services/testing contract research agreements between and managed by The University of Sydney or the NSLHD. The authors report no other conflicts of interest in this work.

\section{References}

1. Hawker GA. Osteoarthritis is a serious disease. Clin Exp Rheumatol. 2019;37 Suppl 120(5):3-6.

2. OARSI TP-cCfOPo. OARSI White Paper- OA as a Serious Disease; 2016.

3. Safiri S, Kolahi AA, Smith E, et al. Global, regional and national burden of osteoarthritis 1990-2017: a systematic analysis of the Global Burden of Disease Study 2017. Ann Rheum Dis. 2020;79 (6):819-828. doi:10.1136/annrheumdis-2019-216515

4. Neogi T. The epidemiology and impact of pain in osteoarthritis. Osteoarthritis Cartilage. 2013;21(9):1145-1153. doi:10.1016/j. joca.2013.03.018

5. Murphy L, Schwartz TA, Helmick CG, et al. Lifetime risk of symptomatic knee osteoarthritis. Arthritis Rheum. 2008;59 (9):1207-1213. doi:10.1002/art.24021

6. Hootman JM, Helmick CG, Barbour KE, Theis KA, Boring MA. Updated projected prevalence of self-reported doctor-diagnosed arthritis and arthritis-attributable activity limitation among US Adults, 2015-2040. Arthritis Rheumatol. 2016;68(7):1582-1587. doi:10.1002/art.39692

7. WHO. Chronic rheumatic conditions; Published 2021. https:// www.who.int/chp/topics/rheumatic/en/. Accessed June 7, 2021.

8. Osteoarthritis and Allied Disorders. In: The Burden of Musculoskeletal Diseases in the United States (BMUS). Third ed. 2014.

9. Lo J, Chan L, Flynn S. A systematic review of the incidence, prevalence, costs, and activity and work limitations of amputation, osteoarthritis, rheumatoid arthritis, back pain, multiple sclerosis, spinal cord injury, stroke, and traumatic brain injury in the United States: a 2019 Update. Arch Phys Med Rehabil. 2021;102(1):115-131. doi:10.1016/j.apmr.2020.04.001

10. Puig-Junoy J, Ruiz Zamora A. Socio-economic costs of osteoarthritis: a systematic review of cost-of-illness studies. Semin Arthritis Rheum. 2015;44(5):531-541. doi:10.1016/j.semarthrit.2014.10.012

11. Leyland KM, Gates LS, Sanchez-Santos MT, et al. Knee osteoarthritis and time-to all-cause mortality in six community-based cohorts: an international meta-analysis of individual participant-level data. Aging Clin Exp Res. 2021;33(3):529-545. doi:10.1007/s40520-020-01762-2

12. Bannuru RR, Osani MC, Vaysbrot EE, et al. OARSI guidelines for the non-surgical management of knee, hip, and polyarticular osteoarthritis. Osteoarthritis Cartilage. 2019;27(11):1578-1589. doi:10.1016/j.joca.2019.06.011 
13. Kolasinski SL, Neogi T, Hochberg MC, et al. 2019 American college of rheumatology/arthritis foundation guideline for the management of osteoarthritis of the hand, hip, and knee. Arthritis Care Res. 2020;72(2):149-162. doi:10.1002/acr.24131

14. Weinstein AM, Rome BN, Reichmann WM, et al. Estimating the burden of total knee replacement in the United States. $J$ Bone Joint Surg Am. 2013;95(5):385-392.

15. Shane Anderson A, Loeser RF. Why is osteoarthritis an age-related disease? Best Pract Res Clin Rheumatol. 2010;24 (1):15-26. doi:10.1016/j.berh.2009.08.006

16. Loeser RF, Goldring SR, Scanzello CR, Goldring MB. Osteoarthritis: a disease of the joint as an organ. Arthritis Rheum. 2012;64(6):1697-1707. doi:10.1002/art.34453

17. Oo WM, Yu SP, Daniel MS, Hunter DJ. Disease-modifying drugs in osteoarthritis: current understanding and future therapeutics. Expert Opin Emerg Drugs. 2018;23(4):331-347. doi:10.1080/ 14728214.2018.1547706

18. Food and Drug Administration of the United States. Osteoarthritis: structural Endpoints for the Development of Drugs; 2018.

19. Food and Drug Administration of the United States. Draft guidance for industry: clinical development programs for drugs, devices, and biological products intended for the treatment of osteoarthritis (OA); 1999.

20. European Medicines Agency. Clinical investigation of medicinal products used in the treatment of osteoarthritis; 2010.

21. Felson DT. Identifying different osteoarthritis phenotypes through epidemiology. Osteoarthritis Cartilage. 2010;18(5):601-604. doi:10.1016/j.joca.2010.01.007

22. Bierma-Zeinstra SM, Verhagen AP. Osteoarthritis subpopulations and implications for clinical trial design. Arthritis Res Ther. 2011;13(2):213. doi:10.1186/ar3299

23. Karsdal MA, Michaelis M, Ladel C, et al. Disease-modifying treatments for osteoarthritis (DMOADs) of the knee and hip: lessons learned from failures and opportunities for the future. Osteoarthritis Cartilage. 2016;24(12):2013-2021. doi:10.1016/j. joca.2016.07.017

24. Mobasheri A, Saarakkala S, Finnilä M, Karsdal MA, Bay-Jensen A-C, van Spil WE. Recent advances in understanding the phenotypes of osteoarthritis. F1000Res. 2019;8:F1000Faculty Rev2091. doi:10.12688/f1000research.20575.1

25. Dell'Isola A, Allan R, Smith SL, Marreiros SS, Steultjens M. Identification of clinical phenotypes in knee osteoarthritis: a systematic review of the literature. BMC Musculoskelet Disord. 2016;17(1):425. doi:10.1186/s12891-016-1286-2

26. Van Spil WE, Kubassova O, Boesen M, Bay-Jensen AC, Mobasheri A. Osteoarthritis phenotypes and novel therapeutic targets. Biochem Pharmacol. 2019;165:41-48. doi:10.1016/j.bcp.2019.02.037

27. Jameson JL, Longo DL. Precision medicine--personalized, problematic, and promising. $N$ Engl J Med. 2015;372 (23):2229-2234. doi:10.1056/NEJMsb1503104

28. Deveza LA, Nelson AE, Loeser RF. Phenotypes of osteoarthritis: current state and future implications. Clin Exp Rheumatol. 2019;37 Suppl 120(5):64-72.

29. Mobasheri A, van Spil WE, Budd E, et al. Molecular taxonomy of osteoarthritis for patient stratification, disease management and drug development: biochemical markers associated with emerging clinical phenotypes and molecular endotypes. Curr Opin Rheumatol. 2019;31(1):80-89. doi:10.1097/BOR.0000000000000567

30. Oo WM, Hunter DJ. Disease modification in osteoarthritis: are we there yet? Clin Exp Rheumatol. 2019;37 Suppl 120(5):135-140.

31. Troeberg L, Nagase H. Proteases involved in cartilage matrix degradation in osteoarthritis. Biochim Biophys Acta. 2012;1824 (1):133-145.

32. Wang M, Sampson ER, Jin H, et al. MMP13 is a critical target gene during the progression of osteoarthritis. Arthritis Res Ther. 2013;15(1):R5-R5. doi:10.1186/ar4133
33. Glasson SS, Askew R, Sheppard B, et al. Deletion of active ADAMTS5 prevents cartilage degradation in a murine model of osteoarthritis. Nature. 2005;434(7033):644-648. doi:10.1038/ nature 03369

34. Krzeski P, Buckland-Wright C, Balint G, et al. Development of musculoskeletal toxicity without clear benefit after administration of PG-116800, a matrix metalloproteinase inhibitor, to patients with knee osteoarthritis: a randomized, 12-month, double-blind, placebo-controlled study. Arthritis Res Ther. 2007;9(5):R109. doi:10.1186/ar2315

35. Brebion F, Gosmini R, Deprez P, et al. Discovery of GLPG1972/ S201086, a potent, selective, and orally bioavailable ADAMTS-5 inhibitor for the treatment of osteoarthritis. J Med Chem. 2021;64 (6):2937-2952. doi:10.1021/acs.jmedchem.0c02008

36. vanderAar E, Deckx H, Van Der Stoep M, et al. Study design of a phase 2 clinical trial with a disease-modifying Osteoarthritis drug candidate GLPG1972/S201086: the roccella trial. Osteoarthritis Cartilage. 2020;28:S499-S500. doi:10.1016/j.joca.2020.02.784

37. Servier. Galapagos and Servier report topline results for ROCCELLA Phase 2 clinical trial with GLPG1972/S201086 in knee osteoarthritis patients. 2020. Available from: https://servier. com/en/communique/galapagos-and-servier-report-toplineresults-for-roccella-phase-2-clinical-trial-with-glpg1972-s201086in-knee-osteoarthritis-patients/. Accessed 10 June, 2021.

38. Guehring HBT, Goteti K, Sonne J, et al. Safety, tolerability, pharmacokinetics and pharmacodynamics of single ascending doses of the anti-ADAMTS-5 Nanobody ${ }^{\circledR}$, M6495, in healthy male subjects: a phase i, placebo-controlled, first-in-human study [abstract]. Arthritis Rheumatol. 2019;71(suppl):10.

39. Lohmander LS, Hellot S, Dreher D, et al. Intraarticular sprifermin (recombinant human fibroblast growth factor 18) in knee osteoarthritis: a randomized, double-blind, placebo-controlled trial. Arthritis Rheumatol. 2014;66(7):1820-1831. doi:10.1002/art.38614

40. Sennett ML, Meloni GR, Farran AJE, Guehring H, Mauck RL, Dodge GR. Sprifermin treatment enhances cartilage integration in an in vitro repair model. J Orthopaed Res. 2018;36 (10):2648-2656. doi:10.1002/jor.24048

41. Gigout A, Guehring H, Froemel D, et al. Sprifermin (rhFGF18) enables proliferation of chondrocytes producing a hyaline cartilage matrix. Osteoarthritis Cartilage. 2017;25(11):1858-1867. doi:10.1016/j.joca.2017.08.004

42. Eckstein F, Wirth W, Guermazi A, Maschek S, Aydemir A. Brief report: intraarticular sprifermin not only increases cartilage thickness, but also reduces cartilage loss: location-independent post hoc analysis using magnetic resonance imaging. Arthritis Rheumatol. 2015;67(11):2916-2922. doi:10.1002/art.39265

43. Roemer FW, Aydemir A, Lohmander S, et al. Structural effects of sprifermin in knee osteoarthritis: a post-hoc analysis on cartilage and non-cartilaginous tissue alterations in a randomized controlled trial. BMC Musculoskelet Disord. 2016;17:267. doi:10.1186/s12891-016-1128-2

44. Dahlberg LE, Aydemir A, Muurahainen N, et al. A first-inhuman, double-blind, randomised, placebo-controlled, dose ascending study of intra-articular rhFGF18 (sprifermin) in patients with advanced knee osteoarthritis. Clin Exp Rheumatol. 2016;34(3):445-450.

45. Hochberg MC, Guermazi A, Guehring H, et al. Effect of intra-articular sprifermin vs placebo on femorotibial joint cartilage thickness in patients with osteoarthritis: the FORWARD Randomized Clinical Trial. JAMA. 2019;322(14):1360-1370. doi:10.1001/jama.2019.14735

46. Kwoh CK, Guehring H, Hannon MJ, Aydemir A. Clinical relevance of structural measures in knee osteoarthritis: baseline values and change from baseline discriminate patients subsequently receiving knee replacement. Arthritis Rheumatol Conf. 2017;69(Supplement):10. 
47. Previtali D, Merli G, Di Laura Frattura G, Candrian C, Zaffagnini S, Filardo G. The long-lasting effects of "placebo injections" in knee osteoarthritis: a meta-analysis. Cartilage. 2020;1947603520906597.

48. Hans guehring JK, Moreau F, Daelken B, et al. Hochberg cartilage thickness modification with sprifermin in knee osteoarthritis patients translates into symptomatic improvement over placebo in patients at risk of further structural and symptomatic progression: post-hoc analysis of a phase II Trial. Arthritis Rheumatol 2019. 2019;71(suppl 10)

49. Bellamy N, Hochberg M, Tubach F, et al. Development of multinational definitions of minimal clinically important improvement and patient acceptable symptomatic state in osteoarthritis. Arthritis Care Res. 2015;67(7):972-980. doi:10.1002/acr.22538

50. Eckstein F, Kraines JL, Aydemir A, Wirth W, Maschek S, Hochberg MC. Intra-articular sprifermin reduces cartilage loss in addition to increasing cartilage gain independent of location in the femorotibial joint: post-hoc analysis of a randomised, placebo-controlled phase II clinical trial. Ann Rheum Dis. 2020;79(4):525-528. doi:10.1136/annrheumdis-2019-216453

51. Day TF, Guo X, Garrett-Beal L, Yang Y. Wnt/beta-catenin signaling in mesenchymal progenitors controls osteoblast and chondrocyte differentiation during vertebrate skeletogenesis. Dev Cell. 2005;8(5):739-750. doi:10.1016/j.devcel.2005.03.016

52. Gelse K, Ekici AB, Cipa F, et al. Molecular differentiation between osteophytic and articular cartilage--clues for a transient and permanent chondrocyte phenotype. Osteoarthritis Cartilage. 2012;20(2):162-171. doi:10.1016/j.joca.2011.12.004

53. Lories RJ, Monteagudo S. Review article: is wnt signaling an attractive target for the treatment of osteoarthritis? Rheumatol Ther. 2020;7(2):259-270. doi:10.1007/s40744-020-00205-8

54. Kovács B, Vajda E, Nagy EE. Regulatory Effects and Interactions of the Wnt and OPG-RANKL-RANK signaling at the bone-cartilage interface in osteoarthritis. Int J Mol Sci. 2019;20 (18):4653. doi:10.3390/ijms20184653

55. Chan BY, Fuller ES, Russell AK, et al. Increased chondrocyte sclerostin may protect against cartilage degradation in osteoarthritis. Osteoarthritis Cartilage. 2011;19(7):874-885. doi:10.1016/j.joca.2011.04.014

56. Cherifi C, Monteagudo S, Lories RJ. Promising targets for therapy of osteoarthritis: a review on the Wnt and TGF- $\beta$ signalling pathways. Ther Adv Musculoskelet Dis. 2021;13:1759720X211006959. doi:10.1177/1759720X211006959

57. Wang Y, Fan X, Xing L, Tian F. Wnt signaling: a promising target for osteoarthritis therapy. Cell Commun Signa. 2019;17(1):97 doi:10.1186/s12964-019-0411-x

58. Deshmukh V, O'Green AL, Bossard C, et al. Modulation of the Wnt pathway through inhibition of CLK2 and DYRK1A by lorecivivint as a novel, potentially disease-modifying approach for knee osteoarthritis treatment. Osteoarthritis Cartilage. 2019;27(9):1347-1360. doi:10.1016/j.joca.2019.05.006

59. Hood J, Barroga C, Hu Y, Deshmukh V. OP0069 Discovery of a small molecule inhibitor of the WNT Pathway (SM04690) as a potential disease modifying treatment for knee osteoarthritis. Ann Rheum Dis. 2016;75(Suppl 2):81.

60. Deshmukh V, Hu H, Barroga C, et al. A small-molecule inhibitor of the Wnt pathway (SM04690) as a potential disease modifying agent for the treatment of osteoarthritis of the knee. Osteoarthritis Cartilage. 2018;26(1):18-27. doi:10.1016/j.joca.2017.08.015

61. Yazici YMT, Gibofsky A, Lane NE, et al. Results from a 52 week randomized, double-blind, placebo-controlled, phase 2 study of a novel, intra-articular, wnt pathway inhibitor (SM04690) for the Treatment of Knee Osteoarthritis [abstract]. Arthritis Rheumatol. 2017;69(suppl 10).
62. Yazici Y, McAlindon TE, Gibofsky A, et al. Lorecivivint, a Novel Intraarticular CDC-like Kinase 2 and dual-specificity tyrosine phosphorylation-regulated kinase 1a inhibitor and wnt pathway modulator for the treatment of knee osteoarthritis: a Phase II Randomized Trial. Arthritis Rheumatol. 2020;72(10):1694-1706. doi:10.1002/art.41315

63. Yazici Y, McAlindon TE, Gibofsky A, et al. A Phase 2b randomized trial of lorecivivint, a novel intra-articular CLK2/DYRK1A inhibitor and Wnt pathway modulator for knee osteoarthritis. Osteoarthritis Cartilage. 2021;29(5):654-666. doi:10.1016/j. joca.2021.02.004

64. Simsek I, Swearingen C, Kennedy S, et al. OP0188 Integrated safety summary of the novel, intra-articular agent Lorecivivint (SM04690), A CLK/DYRK1A inhibitor that modulates the WNT pathway, in subjects with knee osteoarthritis. Ann Rheum Dis. 2020;79(Suppl 1):117. doi:10.1136/annrheumdis-2020-eular.6635

65. Zhai G, Dore J, Rahman P. TGF-beta signal transduction pathways and osteoarthritis. Rheumatol Int. 2015;35(8):1283-1292. doi:10.1007/s00296-015-3251-z

66. Kizawa H, Kou I, Iida A, et al. An aspartic acid repeat polymorphism in asporin inhibits chondrogenesis and increases susceptibility to osteoarthritis. Nat Genet. 2005;37(2):138-144. doi: $10.1038 /$ ng 1496

67. van der Kraan PM. Differential role of transforming growth factor-beta in an osteoarthritic or a healthy joint. $J$ Bone Metab. 2018;25(2):65-72. doi:10.11005/jbm.2018.25.2.65

68. Dai G, Xiao H, Liao J, et al. Osteocyte TGF $\beta 1-\operatorname{Smad} 2 / 3$ is positively associated with bone turnover parameters in subchondral bone of advanced osteoarthritis. Int J Mol Med. 2020;46(1):167-178.

69. Guermazi A, Kalsi G, Niu J, et al. Structural effects of intraarticular TGF- $\beta 1$ in moderate to advanced knee osteoarthritis: MRI-based assessment in a randomized controlled trial. $B M C$ Musculoskelet Disord. 2017;18(1):461.

70. Lim CL, Lee YJ, Cho JH, et al. Immunogenicity and immunomodulatory effects of the human chondrocytes, hChonJ. BMC Musculoskelet Disord. 2017;18(1):199. doi:10.1186/s12891-0171547-8

71. Hunter RC D, Wang M, Noh M. Overall Safety of TG-C: safety analysis of phase-1, phase-2 and long-term safety trials [Abstract]. Osteoarthritis Cartilage. 2020;28.

72. Lee $\mathrm{H}$, Kim H, Seo J, et al. TissueGene-C promotes an anti-inflammatory micro-environment in a rat monoiodoacetate model of osteoarthritis via polarization of M2 macrophages leading to pain relief and structural improvement. Inflammopharmacology. 2020;28(5):1237-1252. doi:10.1007/s10787-020-00738-y

73. Cho J, Kim T, Shin J, Kang S, Lee B. A Phase III clinical results of INVOSSATM(TissueGene C): a clues for the potential disease modifying OA drug. Cytotherapy. 2017;19(5):S148. doi:10.1016/ j.jcyt.2017.02.221

74. Kim MK, Ha CW, In Y, et al. A multicenter, double-blind, phase iii clinical trial to evaluate the efficacy and safety of a cell and gene therapy in knee osteoarthritis patients. Hum Gene Ther Clin Dev. 2018. doi:10.1089/humc.2017.249

75. Hyun-woo N. Kolon's stance on Invossa draws backlash; 2019.

76. Kolon TissueGene cleared to resume US Phase III trial for Invossa. Thepharmaletter. 2020. Available from: https://www.the pharmaletter.com/article/kolon-tissuegene-cleared-to-resume-usphase-iii-trial-for-invossa. Accessed 10 June, 2021.

77. Latourte A, Kloppenburg M, Richette P. Emerging pharmaceutical therapies for osteoarthritis. Nat Rev Rheumatol. 2020;16 (12):673-688.

78. Loeser RF. Aging and osteoarthritis: the role of chondrocyte senescence and aging changes in the cartilage matrix. Osteoarthritis Cartilage. 2009;17(8):971-979. doi:10.1016/j. joca.2009.03.002 
79. Coppé JP, Patil CK, Rodier F, et al. Senescence-associated secretory phenotypes reveal cell-nonautonomous functions of oncogenic RAS and the p53 tumor suppressor. PLoS Biol. 2008;6 (12):2853-2868. doi:10.1371/journal.pbio.0060301

80. Ferreira-Gonzalez S, Lu WY, Raven A, et al. Paracrine cellular senescence exacerbates biliary injury and impairs regeneration. Nat Commun. 2018;9(1):1020. doi:10.1038/s41467-018-03299-5

81. Kim E-C, Kim J-R. Senotherapeutics: emerging strategy for healthy aging and age-related disease. BMB Rep. 2019;52 (1):47-55. doi:10.5483/BMBRep.2019.52.1.293

82. Yousefzadeh MJ, Zhu Y, McGowan SJ, et al. Fisetin is a senotherapeutic that extends health and lifespan. EBioMedicine. 2018;36:18-28. doi:10.1016/j.ebiom.2018.09.015

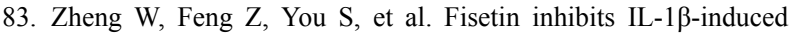
inflammatory response in human osteoarthritis chondrocytes through activating SIRT1 and attenuates the progression of osteoarthritis in mice. Int Immunopharmacol. 2017;45:135-147. doi:10.1016/j.intimp.2017.02.009

84. Jeon OH, Kim C, Laberge R-M, et al. Local clearance of senescent cells attenuates the development of post-traumatic osteoarthritis and creates a pro-regenerative environment. Nat Med. 2017;23(6):775-781. doi:10.1038/nm.4324

85. Yohn COBR, Lussier S, Berridge C, et al. Senescent synoviocytes in knee osteoarthritis correlate with disease biomarkers, synovitis, and knee pain [abstract]. Arthritis Rheumatol. 2019;71(suppl 10).

86. Unity Biotechnology Inc. UNITY Biotechnology Announces 12-week data from UBX0101 Phase 2 clinical study in patients with painful osteoarthritis of the knee. 2020. Available from: https://www.globenewswire.com/news-release/2020/08/17/ 2079116/0/en/UNITY-Biotechnology-Announces-12-week-datafrom-UBX0101-Phase-2-Clinical-Study-in-Patients-with-PainfulOsteoarthritis-of-the-Knee.html. Accessed 10, June 2021.

87. Hügle T, Geurts J. What drives osteoarthritis?-synovial versus subchondral bone pathology. Rheumatology (Oxford). 2017;56 (9):1461-1471. doi:10.1093/rheumatology/kew389

88. Moretti A, Paoletta M, Liguori S, et al. The rationale for the intra-articular administration of clodronate in osteoarthritis. Int J Mol Sci. 2021;22(5). doi:10.3390/ijms22052693.

89. Hu Y, Chen X, Wang S, Jing Y, Su J. Subchondral bone microenvironment in osteoarthritis and pain. Bone Res. 2021;9(1):20. doi:10.1038/s41413-021-00147-z

90. Zhu X, Chan YT, Yung PSH, Tuan RS, Jiang Y. Subchondral bone remodeling: a therapeutic target for osteoarthritis. Front Cell Dev Biol. 2021;8:607764. doi:10.3389/fcell.2020.607764

91. Drake FH, Dodds RA, James IE, et al. Cathepsin K, but not cathepsins B, L, or $\mathrm{S}$, is abundantly expressed in human osteoclasts. $J$ Biol Chem. 1996;271(21):12511-12516. doi:10.1074/jbc.271.21.12511

92. Dejica VM, Mort JS, Laverty S, et al. Cleavage of type II collagen by cathepsin $\mathrm{K}$ in human osteoarthritic cartilage. $\mathrm{Am}$ J Pathol. 2008;173(1):161-169. doi:10.2353/ajpath.2008.070494

93. Kozawa E, Nishida Y, Cheng XW, et al. Osteoarthritic change is delayed in a Ctsk-knockout mouse model of osteoarthritis. Arthritis Rheum. 2012;64(2):454-464. doi:10.1002/art.33398

94. Hayami T, Zhuo Y, Wesolowski GA, Pickarski M, Duong LT. Inhibition of cathepsin $\mathrm{K}$ reduces cartilage degeneration in the anterior cruciate ligament transection rabbit and murine models of osteoarthritis. Bone. 2012;50(6):1250-1259. doi:10.1016/j. bone.2012.03.025

95. Conaghan PG, Bowes MA, Kingsbury SR, et al. DiseaseModifying Effects of a Novel Cathepsin K Inhibitor in Osteoarthritis: a Randomized Controlled Trial. Ann Intern Med. 2020;172(2):86-95. doi:10.7326/M19-0675
96. Conaghan PG, Bowes MA, Kingsbury SR, et al. Safety and efficacy of six months' open label extension post-RCT using the novel cathepsin $\mathrm{K}$ inhibitor MIV-711 in patients with knee osteoarthritis. Osteoarthritis Cartilage. 2019;27:S501-S502. doi:10.1016/j.joca.2019.02.564

97. Macica C, Liang G, Nasiri A, Broadus AE. Genetic evidence of the regulatory role of parathyroid hormone-related protein in articular chondrocyte maintenance in an experimental mouse model. Arthritis Rheum. 2011;63(11):3333-3343. doi:10.1002/art.30515

98. Sampson ER, Hilton MJ, Tian Y, et al. Teriparatide as a chondroregenerative therapy for injury-induced osteoarthritis. Sci Transl Med. 2011;3(101):101ra193-101ra193. doi:10.1126/ scitranslmed.3002214

99. Bellido M, Lugo L, Roman-Blas JA, et al. Improving subchondral bone integrity reduces progression of cartilage damage in experimental osteoarthritis preceded by osteoporosis. Osteoarthritis Cartilage. 2011;19(10):1228-1236. doi:10.1016/j.joca.2011.07.003

100. Sun Q, Zhen G, Li TP. et al. Parathyroid hormone attenuates osteoarthritis pain by remodeling subchondral bone in mice. Elife;2021. 10. doi:10.7554/eLife.66532

101. Hopwood B, Tsykin A, Findlay DM, Fazzalari NL. Microarray gene expression profiling of osteoarthritic bone suggests altered bone remodelling, WNT and transforming growth factor- $\beta /$ bone morphogenic protein signalling. Arthritis Res Ther. 2007;9(5): R100. doi:10.1186/ar2301

102. McGuire D, Lane N, Segal N, et al. TPX-100 leads to marked, sustained improvements in subjects with knee osteoarthritis: pre-clinical rationale and results of a controlled clinical trial. Osteoarthritis Cartilage. 2018;26:S243. doi:10.1016/j. joca.2018.02.502

103. McGuire D, Bowes M, Brett A, Miller M, Kumugai Y. Study TPX-100-5: significant reduction in femoral bone shape change 12 months after IA TPX-100 correlates with tibiofemoral cartilage stabilization. Osteoarthritis Cartilage. 2020;28:S37-S38. doi:10.1016/j.joca.2020.02.062

104. Vaysbrot EE, Osani MC, Musetti MC, McAlindon TE, Bannuru RR. Are bisphosphonates efficacious in knee osteoarthritis? A meta-analysis of randomized controlled trials. Osteoarthritis Cartilage. 2018;26(2):154-164. doi:10.1016/j. joca.2017.11.013

105. Fernández-Martín S, López-Peña $\mathrm{M}$, Muñoz F, Permuy $\mathrm{M}$, González-Cantalapiedra A. Bisphosphonates as disease-modifying drugs in osteoarthritis preclinical studies: a systematic review from 2000 to 2020. Arthritis Res Ther. 2021;23(1):60. doi:10.1186/s13075-021-02446-6

106. Kiyomoto K, Iba K, Hanaka M, et al. High bone turnover state under osteoporotic changes induces pain-like behaviors in mild osteoarthritis model mice. J Bone Miner Metab. 2020;38 (6):806-818. doi:10.1007/s00774-020-01124-y

107. Adebayo OO, Ko FC, Wan PT, et al. Role of subchondral bone properties and changes in development of load-induced osteoarthritis in mice. Osteoarthritis Cartilage. 2017;25(12):2108-2118. doi:10.1016/j.joca.2017.08.016

108. Funck-Brentano T, Lin H, Hay E, et al. Targeting Bone Alleviates Osteoarthritis in Osteopenic Mice and Modulates Cartilage Catabolism. PLoS One. 2012;7(3):e33543. doi:10.1371/journal. pone. 0033543

109. Kadri A, Funck-Brentano T, Lin H, et al. Inhibition of bone resorption blunts osteoarthritis in mice with high bone remodelling. Ann Rheum Dis. 2010;69(8):1533-1538. doi:10.1136/ard.2009.124586

110. Frediani B, Toscano C, Falsetti P, et al. Intramuscular Clodronate in Long-Term Treatment of Symptomatic Knee Osteoarthritis: a Randomized Controlled Study. Drugs R D. 2020;20(1):39-45. doi:10.1007/s40268-020-00294-4 
111. Varenna M, Zucchi F, Failoni S, Becciolini A, Berruto M. Intravenous neridronate in the treatment of acute painful knee osteoarthritis: a randomized controlled study. Rheumatology (Oxford). 2015;54(10):1826-1832. doi:10.1093/rheumatology/ kev123

112. Deveza LA, Bierma-Zeinstra SMA, van Spil WE, et al. Efficacy of bisphosphonates in specific knee osteoarthritis subpopulations: protocol for an OA Trial Bank systematic review and individual patient data meta-analysis. BMJ Open. 2018;8(12):e023889. doi:10.1136/bmjopen-2018-023889

113. Aitken D, Cai G, Laslett LL, et al. A multicentre randomised double-blind placebo-controlled trial of zoledronic acid for knee osteoarthritis - the zap2 trial. Osteoarthritis Cartilage. 2020;28: S79-S80. doi:10.1016/j.joca.2020.02.121

114. Fu SH, Wang CY, Yang RS, Wu FL, Hsiao FY. Bisphosphonate Use and the Risk of Undergoing Total Knee Arthroplasty in Osteoporotic Patients with Osteoarthritis: a Nationwide Cohort Study in Taiwan. J Bone Joint Surg Am. 2017;99(11):938-946. doi:10.2106/JBJS.16.00385

115. Neogi T, Li S, Peloquin C, Misra D, Zhang Y. Effect of bisphosphonates on knee replacement surgery. Ann Rheum Dis. 2018;77 (1):92-97. doi:10.1136/annrheumdis-2017-211811

116. Hayes KN, Giannakeas V, Wong AKO. Bisphosphonate Use Is Protective of Radiographic Knee Osteoarthritis Progression Among those With Low Disease Severity and Being Non-Overweight: data From the Osteoarthritis Initiative. $J$ Bone Mineral Res. 2020;35(12):2318-2326. doi:10.1002/jbmr.4133

117. Corvol MT, Dumontier MF, Tsagris L, Lang F, Bourguignon J. [Cartilage and vitamin D in vitro (author's transl)]. Annales d'endocrinologie. 1981;42(4-5):482-487. French.

118. Kong C, Wang C, Shi Y, Yan L, Xu J, Qi W. Active vitamin $\mathrm{D}$ activates chondrocyte autophagy to reduce osteoarthritis via mediating the AMPK-mTOR signaling pathway. Biochem Cell Biol. 2020;98(3):434-442. doi:10.1139/bcb-2019-0333

119. Yamamura K, Ohta Y, Mamoto K, Sugama R, Minoda Y, Nakamura H. Effect of eldecalcitol on articular cartilage through the regulation of transcription factor Erg in a murine model of knee osteoarthritis. Biochem Biophys Res Commun. 2018;495 (1):179-184. doi:10.1016/j.bbrc.2017.10.155

120. Boyan BD, Hyzy SL, Pan Q, et al. 24R,25-Dihydroxyvitamin D3 Protects against Articular Cartilage Damage following Anterior Cruciate Ligament Transection in Male Rats. PLoS One. 2016;11 (8):e0161782.

121. Vaishya R, Vijay V, Lama P, Agarwal A. Does vitamin $\mathrm{D}$ deficiency influence the incidence and progression of knee osteoarthritis? - A literature review. J Clin Orthop Trauma. 2019;10(1):9-15. doi:10.1016/j.jcot.2018.05.012

122. Heidari B, Babaei M. Therapeutic and Preventive Potential of Vitamin D Supplementation in Knee Osteoarthritis. ACR Open Rheumatol. 2019;1(5):318-326. doi:10.1002/acr2.1042

123. Sokolove J, Lepus CM. Role of inflammation in the pathogenesis of osteoarthritis: latest findings and interpretations. Ther $A d v$ Musculoskelet Dis. 2013;5(2):77-94. doi:10.1177/ $1759720 X 12467868$

124. Chow YY, Chin K-Y. The Role of Inflammation in the Pathogenesis of Osteoarthritis. Mediators Inflamm. 2020;2020:8293921. doi:10.1155/2020/8293921

125. Dougados M, Nguyen M, Berdah L, Mazieres B, Vignon E, Lequesne M. Evaluation of the structure-modifying effects of diacerein in hip osteoarthritis: ECHODIAH, a three-year, placebo-controlled trial. Evaluation of the Chondromodulating Effect of Diacerein in OA of the Hip. Arthritis Rheum. 2001;44 (11):2539-2547. doi:10.1002/1529-0131(200111)44:11<2539: AID-ART434>3.0.CO;2-T
126. Smith GN Jr, Myers SL, Brandt KD, Mickler EA, Albrecht ME. Diacerhein treatment reduces the severity of osteoarthritis in the canine cruciate-deficiency model of osteoarthritis. Arthritis Rheum. 1999;42(3):545-554. doi:10.1002/1529-0131(199904) 42:3<545::AID-ANR20>3.0.CO;2-4

127. Hwa SY, Burkhardt D, Little C, Ghosh P. The effects of orally administered diacerein on cartilage and subchondral bone in an ovine model of osteoarthritis. J Rheumatol. 2001;28(4):825-834.

128. Permuy M, Guede D, López-Peña M, Muñoz F, Caeiro J-R, González-Cantalapiedra A. Comparison of various SYSADOA for the osteoarthritis treatment: an experimental study in rabbits. BMC Musculoskelet Disord. 2015;16:120. doi:10.1186/s12891015-0572-8

129. Permuy M, Guede D, López-Peña M, Muñoz F, Caeiro J-R, González-Cantalapiedra A. Effects of diacerein on cartilage and subchondral bone in early stages of osteoarthritis in a rabbit model. BMC Vet Res. 2015;11:143. doi:10.1186/s12917-0150458-x

130. Fidelix TS, Macedo CR, Maxwell LJ, Fernandes Moca Trevisani V, Diacerein for osteoarthritis. Cochrane Database Syst Rev. 2014;2:Cd005117. doi:10.1002/14651858.CD005117. pub3

131. European Medicines Agency. PRAC recommends suspension of diacerein-containing medicines; 2013.

132. European Medicines Agency. PRAC re-examines diacerein and recommends that it remain available with restrictions; 2014.

133. Pavelka K, Bruyère $\mathrm{O}$, Cooper $\mathrm{C}$, et al. Diacerein: benefits, Risks and Place in the Management of Osteoarthritis. An Opinion-Based Report from the ESCEO. Drugs Aging. 2016;33 (2):75-85. doi:10.1007/s40266-016-0347-4

134. Pelletier JP, Raynauld JP, Dorais M, et al. An international, multicentre, double-blind, randomized study (DISSCO): effect of diacerein vs celecoxib on symptoms in knee osteoarthritis. Rheumatology (Oxford). 2020;59(12):3858-3868. doi:10.1093/ rheumatology/keaa072

135. Mathiessen A, Conaghan PG. Synovitis in osteoarthritis: current understanding with therapeutic implications. Arthritis Res Ther. 2017;19(1):18. doi:10.1186/s13075-017-1229-9

136. Goldring MB. Anticytokine therapy for osteoarthritis. Expert Opin Biol Ther. 2001;1(5):817-829. doi:10.1517/ 14712598.1.5.817

137. Leuty R. Xoma's headline drug fails 2nd clinical trial in three years. San Francisco Business Times; 2014.

138. Cohen SB, Proudman S, Kivitz AJ, et al. A randomized, double-blind study of AMG 108 (a fully human monoclonal antibody to IL-1R1) in patients with osteoarthritis of the knee. Arthritis Res Ther. 2011;13(4):R125-R125. doi:10.1186/ar3430

139. Kloppenburg M, Peterfy C, Haugen IK, et al. Phase IIa, placebocontrolled, randomised study of lutikizumab, an anti-interleukin $-1 \alpha$ and anti-interleukin- $1 \beta$ dual variable domain immunoglobulin, in patients with erosive hand osteoarthritis. Ann Rheum Dis. 2019;78(3):413-420.

140. Fleischmann RM, Bliddal H, Blanco FJ, et al. A Phase II Trial of Lutikizumab, an Anti-Interleukin- $1 \alpha / \beta$ Dual Variable Domain Immunoglobulin, in Knee Osteoarthritis Patients With Synovitis. Arthritis Rheumatol. 2019;71(7):1056-1069. doi:10.1002/art.40840

141. Chevalier X, Goupille P, Beaulieu AD, et al. Intraarticular injection of anakinra in osteoarthritis of the knee: a multicenter, randomized, double-blind, placebo-controlled study. Arthritis Rheum. 2009;61(3):344-352. doi:10.1002/art.24096

142. Aitken D, Laslett LL, Pan F, et al. A randomised double-blind placebo-controlled crossover trial of HUMira (adalimumab) for erosive hand OsteoaRthritis - the HUMOR trial. Osteoarthritis Cartilage. 2018;26(7):880-887. doi:10.1016/j.joca.2018.02.899 
143. Chevalier X, Ravaud P, Maheu E, et al. Adalimumab in patients with hand osteoarthritis refractory to analgesics and NSAIDs: a randomised, multicentre, double-blind, placebo-controlled trial. Ann Rheum Dis. 2015;74(9):1697-1705. doi:10.1136/annrheumdis-2014-205348

144. Verbruggen G, Wittoek R, Vander Cruyssen B, Elewaut D. Tumour necrosis factor blockade for the treatment of erosive osteoarthritis of the interphalangeal finger joints: a double blind, randomised trial on structure modification. Ann Rheum Dis. 2012;71(6):891-898. doi:10.1136/ard.2011.149849

145. Kloppenburg M, Ramonda R, Bobacz K, et al. Etanercept in patients with inflammatory hand osteoarthritis (EHOA): a multicentre, randomised, double-blind, placebo-controlled trial. Ann Rheum Dis. 2018;77(12):1757-1764. doi:10.1136/annrheumdis-2018-213202

146. Persson MSM, Sarmanova A, Doherty M, Zhang W. Conventional and biologic disease-modifying anti-rheumatic drugs for osteoarthritis: a meta-analysis of randomized controlled trials. Rheumatology (Oxford). 2018.

147. Schieker M, Conaghan PG, Mindeholm L, et al. Effects of Interleukin-1 $\beta$ Inhibition on Incident Hip and Knee Replacement: exploratory Analyses From a Randomized, DoubleBlind, Placebo-Controlled Trial. Ann Intern Med. 2020;173 (7):509-515. doi:10.7326/M20-0527

148. Stannus O, Jones G, Cicuttini F, et al. Circulating levels of IL-6 and TNF- $\alpha$ are associated with knee radiographic osteoarthritis and knee cartilage loss in older adults. Osteoarthritis Cartilage. 2010;18(11):1441-1447. doi:10.1016/j.joca.2010.08.016

149. Kamiya N, Kuroyanagi G, Aruwajoye O, Kim HKW. IL6 receptor blockade preserves articular cartilage and increases bone volume following ischemic osteonecrosis in immature mice. Osteoarthritis Cartilage. 2019;27(2):326-335. doi:10.1016/j. joca.2018.10.010

150. Latourte A, Cherifi C, Maillet J, et al. Systemic inhibition of IL-6/ Stat3 signalling protects against experimental osteoarthritis. Ann Rheum Dis. 2017;76(4):748-755. doi:10.1136/annrheumdis-2016209757

151. de Hooge AS, van de Loo FA, Bennink MB, et al. gene knock out mice developed more advanced osteoarthritis upon aging. Osteoarthritis Cartilage. 2005;13(1):66-73. doi:10.1016/j. joca.2004.09.011

152. Akeson G, Malemud CJ. A Role for Soluble IL-6 Receptor in Osteoarthritis. J Funct Morphol Kinesiol. 2017;2(3):27. doi:10.3390/jfmk2030027

153. Wiegertjes R, van de Loo FAJ, Blaney Davidson EN. A roadmap to target interleukin-6 in osteoarthritis. Rheumatol. 2020;59 (10):2681-2694. doi:10.1093/rheumatology/keaa248

154. Richette P, Latourte A, Sellam J, et al. Efficacy of tocilizumab in patients with hand osteoarthritis: double blind, randomised, placebo-controlled, multicentre trial. Ann Rheum Dis. 2021;80 (3):349-355. doi:10.1136/annrheumdis-2020-218547

155. Moroguchi A, Ishimura K, Okano K, Wakabayashi H, Maeba T, Maeta H. Interleukin-10 suppresses proliferation and remodeling of extracellular matrix of cultured human skin fibroblasts. Eur Surg Res. 2004;36(1):39-44. doi:10.1159/000075073

156. John T, Müller RD, Oberholzer A, et al. Interleukin-10 modulates pro-apoptotic effects of TNF-alpha in human articular chondrocytes in vitro. Cytokine. 2007;40(3):226-234. doi:10.1016/j. cyto.2007.10.002

157. Felson D, Niu J, Sack B, Aliabadi P, McCullough C, Nevitt MC. Progression of osteoarthritis as a state of inertia. AnnRheumDis. 2013;72(6):924-929.

158. Hunter DJ, McDougall JJ, Keefe FJ. The symptoms of osteoarthritis and the genesis of pain. Rheum Dis Clin North Am. 2008;34(3):623-643. doi:10.1016/j.rdc.2008.05.004
159. Hunter D, Nevitt M, Lynch J, et al. Longitudinal validation of periarticular bone area and $3 \mathrm{D}$ shape as biomarkers for knee OA progression? Data from the FNIH OA Biomarkers Consortium. Ann Rheum Dis. 2016;75(9):1607-1614. doi:10.1136/annrheumdis-2015-207602

160. Hunter DJ, Nevitt M, Losina E, Kraus V. Biomarkers for osteoarthritis: current position and steps towards further validation. Best Pract Res Clin Rheumatol. 2014;28(1):61-71.

161. Kraus VB, Simon LS, Katz JN, et al. Proposed study designs for approval based on a surrogate endpoint and a post-marketing confirmatory study under FDA's accelerated approval regulations for disease modifying osteoarthritis drugs. Osteoarthritis Cartilage. 2019;27(4):571-579. doi:10.1016/j.joca.2018.11.002

162. Roemer FW, Kwoh CK, Hayashi D, Felson DT, Guermazi A. The role of radiography and MRI for eligibility assessment in DMOAD trials of knee OA. Nat Rev Rheumatol. 2018;14 (6):372-380. doi:10.1038/s41584-018-0010-z

163. Eckstein F, Le Graverand MP. Plain radiography or magnetic resonance imaging (MRI): which is better in assessing outcome in clinical trials of disease-modifying osteoarthritis drugs? Summary of a debate held at the World Congress of Osteoarthritis 2014. Semin Arthritis Rheum. 2015;45 (3):251-256. doi:10.1016/j.semarthrit.2015.06.001

164. Hunter DJ, Altman RD, Cicuttini F, et al. OARSI Clinical Trials Recommendations: knee imaging in clinical trials in osteoarthritis. Osteoarthritis Cartilage. 2015;23(5):698-715. doi:10.1016/j.joca.2015.03.012

165. Hayashi D, Roemer FW, Guermazi A. Magnetic resonance imaging assessment of knee osteoarthritis: current and developing new concepts and techniques. Clin Exp Rheumatol. 2019;37 Suppl 120(5):88-95.

166. Oo WM, Linklater JM, Hunter DJ. Imaging in knee osteoarthritis. Curr Opin Rheumatol. 2017;29(1):86-95. doi:10.1097/ BOR.0000000000000350

167. Hafezi-Nejad N, Guermazi A, Demehri S, Roemer FW. New imaging modalities to predict and evaluate osteoarthritis progression. Best Pract Res Clin Rheumatol. 2017;31 (5):688-704. doi:10.1016/j.berh.2018.05.001

168. Kwoh CK, Vina ER, Cloonan YK, Hannon MJ, Boudreau RM, Ibrahim SA. Determinants of patient preferences for total knee replacement: African-Americans and whites. Arthritis Res Ther. 2015;17:348. doi:10.1186/s13075-015-0864-2

169. Vina ER, Ran D, Ashbeck EL, et al. Patient preferences for total knee replacement surgery: relationship to clinical outcomes and stability of patient preferences over 2 years. Semin Arthritis Rheum. 2016;46(1):27-33. doi:10.1016/j.semarthrit.2016.03.012

170. McAlindon TE, Driban JB, Henrotin Y, et al. OARSI Clinical Trials Recommendations: design, conduct, and reporting of clinical trials for knee osteoarthritis. Osteoarthritis Cartilage. 2015;23(5):747-760. doi:10.1016/j.joca.2015.03.005

171. Oo WM, Liu X, Hunter DJ. Pharmacodynamics, efficacy, safety and administration of intra-articular therapies for knee osteoarthritis. Expert Opin Drug Metab Toxicol. 2019;15 (12):1021-1032. doi:10.1080/17425255.2019.1691997

172. Zhang W, Robertson J, Jones AC, Dieppe PA, Doherty M. The placebo effect and its determinants in osteoarthritis: meta-analysis of randomised controlled trials. AnnRheumDis. 2008;67(12):1716-1723.

173. Edwards SH. Intra-articular drug delivery: the challenge to extend drug residence time within the joint. Veterinary j. 2011;190 (1):15-21. doi:10.1016/j.tvj1.2010.09.019

174. Janssen M, Mihov G, Welting T, Thies J, Emans P. Drugs and Polymers for Delivery Systems in OA Joints: clinical Needs and Opportunities. Polymers. 2014;6(3):799-819.

175. Liechty WB, Kryscio DR, Slaughter BV, Peppas NA. Polymers for drug delivery systems. Annu Rev Chem Biomol Eng. 2010;1:149-173. doi:10.1146/annurev-chembioeng-073009-100847 
176. Altman RD, Devji T, Bhandari M, Fierlinger A, Niazi F, Christensen R. Clinical benefit of intra-articular saline as a comparator in clinical trials of knee osteoarthritis treatments: a systematic review and meta-analysis of randomized trials. Semin Arthritis Rheum. 2016;46(2):151-159. doi:10.1016/j.semarthrit.2016.04.003

177. Simsek I, Phalen T, Bedenbaugh A, Phillips M, Tambiah J. Adjusting for the intra-articular placebo effect in knee osteoarthritis therapies [Abstract]. Ann Rheum Dis. 2018;77(Suppl 2):1135-1136.

178. Eitner A, Hofmann GO, Schaible H-G. Mechanisms of Osteoarthritic Pain. Studies in Humans and Experimental Models. Front Mol Neurosci. 2017;10:349. doi:10.3389/fnmol.2017.00349

179. Tonge DP, Pearson MJ, Jones SW. The hallmarks of osteoarthritis and the potential to develop personalised disease-modifying pharmacological therapeutics. Osteoarthritis Cartilage. 2014;22 (5):609-621. doi:10.1016/j.joca.2014.03.004

180. Parry E, Ogollah R, Peat G. Significant pain variability in persons with, or at high risk of, knee osteoarthritis: preliminary investigation based on secondary analysis of cohort data. BMC Musculoskelet Disord. 2017;18(1):80. doi:10.1186/s12891-017-1434-3
181. Mobasheri A, Batt M. An update on the pathophysiology of osteoarthritis. Ann Phys Rehabil Med. 2016;59(5-6):333-339. doi:10.1016/j.rehab.2016.07.004

182. Marson FAL, Bertuzzo CS, Ribeiro JD. Personalized or Precision Medicine? The Example of Cystic Fibrosis. Front Pharmacol. 2017;8:390. doi:10.3389/fphar.2017.00390

183. Siaton BC, Hogans BH, Hochberg MC. Precision medicine in osteoarthritis: not yet ready for prime time. Expert Review Precision Med Drug Develop. 2021;6(1):5-8. doi:10.1080/ 23808993.2020.1842731

184. Bay-Jensen A-C, Henrotin Y, Karsdal M, Mobasheri A. The Need for Predictive, Prognostic, Objective and Complementary Blood-Based Biomarkers in Osteoarthritis (OA). EBioMedicine. 2016;7:4-6. doi:10.1016/j.ebiom.2016.05.004

\section{Publish your work in this journal}

Drug Design, Development and Therapy is an international, peerreviewed open-access journal that spans the spectrum of drug design and development through to clinical applications. Clinical outcomes, patient safety, and programs for the development and effective, safe, and sustained use of medicines are a feature of the journal, which has also been accepted for indexing on PubMed Central. The manuscript management system is completely online and includes a very quick and fair peer-review system, which is all easy to use. Visit http://www. dovepress.com/testimonials.php to read real quotes from published authors. 